Review

\title{
Targeting the STAT3 signaling pathway in cancer: Role of synthetic and natural inhibitors
}

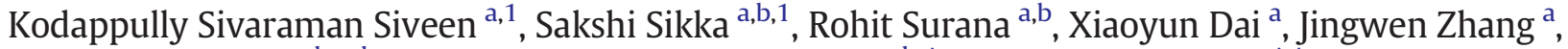 \\ Alan Prem Kumar ${ }^{\text {a,b,c,d }}$, Benny K.H. Tan ${ }^{\text {a }}$, Gautam Sethi ${ }^{\mathrm{a}, \mathrm{b}, *}$, Anupam Bishayee ${ }^{\mathrm{e}, * *}$
}

a Department of Pharmacology, Yong Loo Lin School of Medicine, National University of Singapore, Singapore

b Cancer Science Institute of Singapore, National University of Singapore, Centre for Translational Medicine, Singapore

' School of Biomedical Sciences, Faculty of Health Sciences, Curtin University, Western Australia, Australia

${ }^{\mathrm{d}}$ Department of Biological Sciences, University of North Texas, Denton, TX, USA

e Department of Pharmaceutical Sciences, School of Pharmacy, American University of Health Sciences, Signal Hill, CA, USA

\section{A R T I C L E I N F O}

\section{Article history:}

Received 15 August 2013

Received in revised form 24 December 2013

Accepted 27 December 2013

Available online 2 January 2014

\section{Keywords:}

STAT3

Inhibitors

Tumorigenesis

Inflammation

Proliferation

Metastasis

\begin{abstract}
A B S T R A C T
Signal transducers and activators of transcription (STATs) comprise a family of cytoplasmic transcription factors that mediate intracellular signaling that is usually generated at cell surface receptors and thereby transmit it to the nucleus. Numerous studies have demonstrated constitutive activation of STAT3 in a wide variety of human tumors, including hematological malignancies (leukemias, lymphomas, and multiple myeloma) as well as diverse solid tumors (such as head and neck, breast, lung, gastric, hepatocellular, colorectal and prostate cancers). There is strong evidence to suggest that aberrant STAT3 signaling promotes initiation and progression of human cancers by either inhibiting apoptosis or inducing cell proliferation, angiogenesis, invasion, and metastasis. Suppression of STAT3 activation results in the induction of apoptosis in tumor cells, and accordingly its pharmacological modulation by tyrosine kinase inhibitors, antisense oligonucleotides, decoy nucleotides, dominant negative proteins, RNA interference and chemopreventive agents have been employed to suppress the proliferation of various human cancer cells in culture and tumorigenicity in vivo. However, the identification and development of novel drugs that can target deregulated STAT3 activation effectively remains an important scientific and clinical challenge. This review presents the evidence for critical roles of STAT3 in oncogenesis and discusses the potential for development of novel cancer therapies based on mechanistic understanding of STAT3 signaling cascade.
\end{abstract}

(C) 2013 Elsevier B.V. All rights reserved.

\section{Contents}

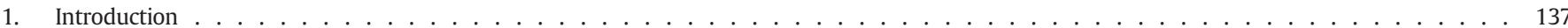

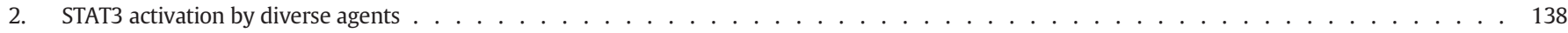

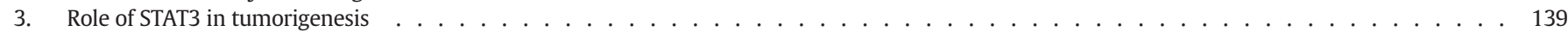

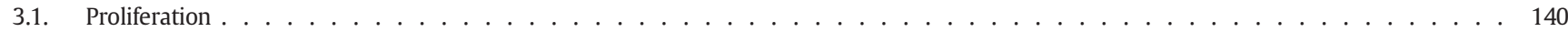

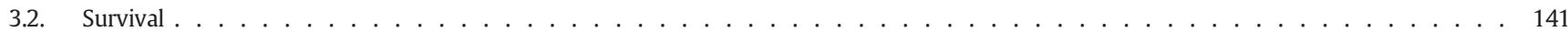

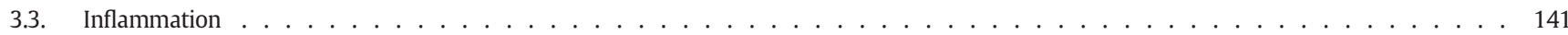

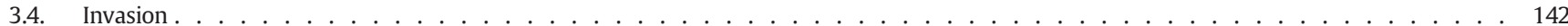

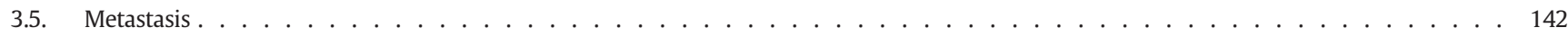

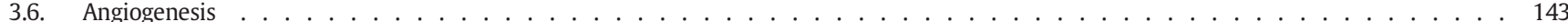

4. Selected natural inhibitors of the STAT3 signaling pathway . . . . . . . . . . . . . . . . . . . . . . . . . . . . . 143

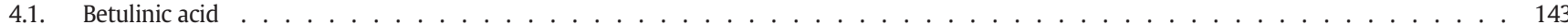

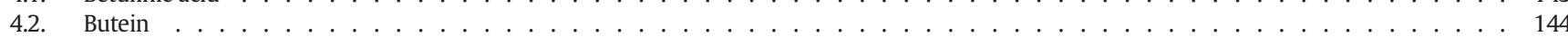

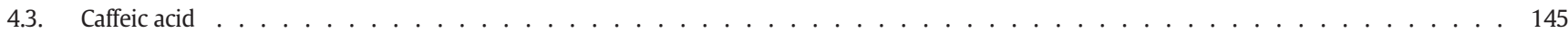

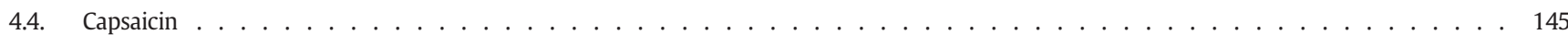

\footnotetext{
* Correspondence to: G. Sethi, Department of Pharmacology, Yong Loo Lin School of Medicine, National University of Singapore, Singapore. Tel.: +65 65163267.

** Correspondence to: A. Bishayee, Department of Pharmaceutical Sciences, School of Pharmacy, American University of Health Sciences, Signal Hill, 1600 East Hill Street, CA 90755, USA Tel.: +15629882278.

E-mail addresses: phcgs@nus.edu.sg (G. Sethi), abishayee@auhs.edu (A. Bishayee).

${ }^{1}$ Both the authors contributed equally to this article.
} 


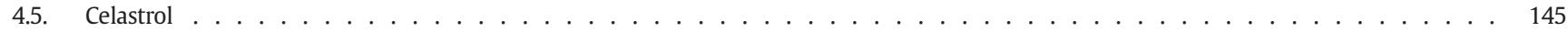

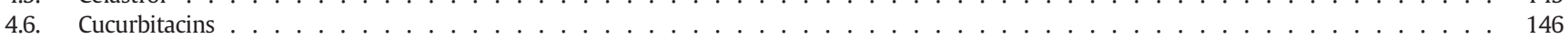

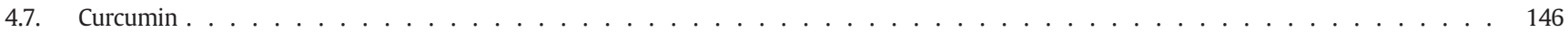

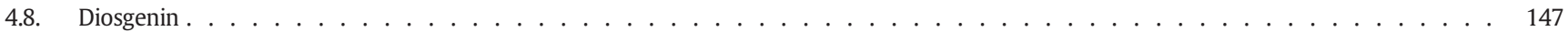

4.9. Guggulsterone . . . . . . . . . . . . . . . . . . . . . . . . . . . . 147

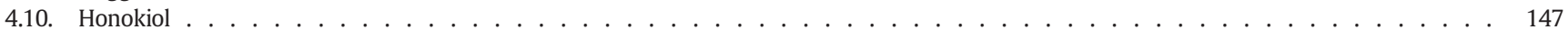

5. Synthetic blockers of STAT3 activation cascade . . . . . . . . . . . . . . . . . . . . . . . . . 147

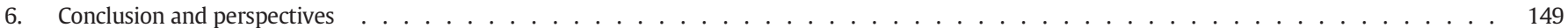

Conflict of interest statement . . . . . . . . . . . . . . . . . . . . . . . . . . . . . . . . . . 149

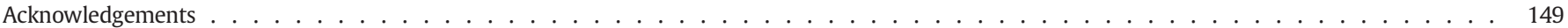

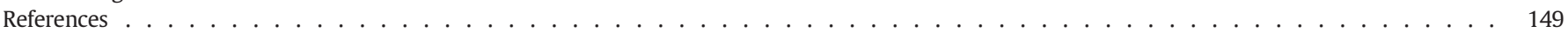

\section{Introduction}

Cancer still remains a deadly disease and second leading cause of mortality worldwide. It is well established that the inheritance of mutated genes and somatic mutations are major causes for cancer development. Large-scale integrated cancer genome characterization efforts including the cancer genome atlas have provided critical insights into the genetic alterations and the potential to identify novel therapeutic targets [1,2]. In addition, lifestyle related factors and environmental agents for instance, obesity, alcohol, tobacco, radiation, environmental pollutants, chronic infections, and highcalorie diet can alter the expression of essential proteins involved in multiple cellular pathways leading to changes in growth, differentiation and apoptosis [3-6]. The molecular mechanisms by which these risk factors induce cancer are becoming increasingly clear. One common phenomena through which these risk factors initiate and promote tumorigenesis is that of chronic inflammation. The critical link between chronic inflammation and cancer is clearly illustrated by the fact that major pro-inflammatory transcription factors nuclear factor- $\kappa \mathrm{B}(\mathrm{NF}-\kappa \mathrm{B})$ and signal transducers and activators of transcription 3 (STAT3), can be activated by several of these important cancer risk factors [7]. These two oncogenic transcription factors have been found to play key roles in tumorigenesis and can thus be considered as potential targets in strategies to prevent or treat cancer.

STAT3 was initially discovered in the context of the specificity of the interferon (IFN) signaling [3,8-11]. STAT3 was at first described in interleukin-6 (IL-6) stimulated hepatocytes as a DNA-binding factor capable of selectively interacting with an enhancer element in the promoter region of acute-phase genes [12]. Later, it was found that STAT3 can be activated by the entire IL- 6 family of cytokines and growth factors such as epidermal growth factor (EGF) [13-15]. Subsequently, the potential oncogenic role of STAT3 was established by the expression of constitutively activated STAT3 in various tumor cell lines including breast, colon, gastric, lung, head and neck, skin, and prostate [16-19]. The STAT family comprises seven members namely, STAT1, STAT2, STAT3, STAT4, STAT5a, STAT5b, and STAT6. They range in size from 750 to 850 amino acids and, based on their functions, the entire STAT family can be divided into two groups. The first group consists of STAT2, STAT4, and STAT6, which are activated through a small number of cytokines and are involved in T-cell development and IFN- $\gamma$ signaling. The second group includes STAT1, STAT3, and STAT5, which are activated in different tissues through various ligands and are involved in IFN- $\gamma$ signaling, development of mammary glands, and embryogenesis. The latter group of STATs plays a key role in oncogenesis since they control cellcycle progression and apoptosis [20]. In the human genome, all the STAT members are organized on 3 different chromosomes, for instance, STAT1 and STAT4 are clustered on chromosome 2, whereas STAT3, STAT5a, and STAT5b are clustered on chromosome 17, while STAT2 and STAT6 are assembled on chromosome 12 [21]. STATs have also been found to be mutated in certain malignancies, e.g. NAB2-STAT6 gene fusions in solitary fibrous tumor (SFT)/hemangiopericytoma [22], STAT3 mutations in T large granular lymphocytic leukemia [23] and
STAT5b mutations in large granular lymphocytic leukemia [24]. Of the STAT family of proteins, STAT3 has received greatest attention since it is involved in a number of oncogenic signaling pathways and intra-cellular signal transduction pathways stimulated by several pro-inflammatory cytokines and growth factors [25].

The STAT3 family of transcription factors also controls numerous physiological processes including development, differentiation, immunity, metabolism, and is aberrantly expressed in pathological conditions such as cancer. Several cytokines and growth factors like IL-6 and EGF family members, as well as hepatocyte growth factor (HGF) mediate activation of STAT3 by phosphorylation. The IL-6 family of cytokines can regulate cell differentiation as well as cell growth. They induce the differentiation of B cells into antibody-forming plasma cells and the differentiation of the myeloid leukemia cell line, M1 into macrophages. Several evidences support a central role of STAT3 in these differentiation processes [26]. STAT3 has also been implicated in B cell differentiation. CD40 is a receptor that is critical for the survival, growth, differentiation, and isotype switching of B lymphocytes. Interestingly, CD40 stimulation can also induce the activation of JAK3 and STAT3 [27].

Initiation of STAT3 activation through ligand (such as IL-6 and IL22 )-receptor interaction results in dimerization of a signal transducer protein, gp130 in the cytoplasm [28,29]. This is followed by induction of Janus-kinase (JAK) phosphorylation and subsequently STAT3 phosphorylation. The JAK family of tyrosine-kinases especially JAK1 mediates the activation of STAT3 [30]. Phosphorylated STAT3 monomers combine to form dimers and translocate into the nucleus to induce transcription of genes involved in cell survival and proliferation [31-34]. However, non-phosphorylated STAT3 is also capable of dimerization and induction of transcription [35]. Once activated, STAT3 controls the expression of anti-apoptotic, pro-proliferative and immune response genes. Moreover, due to up-regulation of upstream signaling pathways attributed to autocrine and paracrine factors that are produced within the tumor microenvironment, STAT3 is constitutively phosphorylated in neoplastic cells [36]. STAT3 transcriptional activity and DNA binding are further enhanced through serine (Ser 727) phosphorylation.

It has been found that cancer cells harboring aberrant STAT3 activity have elevated levels of anti-apoptotic ( $\mathrm{Mcl}-1$ and $\mathrm{Bcl}-\mathrm{xL}$ ) and cell cycle regulating proteins (cyclin D1 and c-Myc) [37-39]. Thus, cancer cells expressing constitutively activated STAT3 are more resistant to apoptosis and chemotherapies aimed at initiating apoptosis. Numerous groups have shown that in vivo administration of STAT3 inhibitors have antitumor effects in human cancer xenograft mouse models. Indeed, a growing number of pre-clinical studies conducted in numerous cancer types, as well as the first Phase 0 clinical trial of oligonucleotide-based decoys of the STAT3 DNA-binding, suggest that STAT3 is a valid therapeutic target for cancer therapy [37]. Phase 0 studies are exploratory studies that often use only a few small doses of a new drug in each patient. They are generally carried out to find whether the drug reaches the tumor, how the drug acts in the human body, and how cancer cells in the human body respond to the drug. For instance, in 2009, Xu and colleagues [40] from Baylor College of Medicine patented a promising group of STAT3 inhibitors that emerged from in silico screening using docking software [41]. 
The current knowledge of STAT3 signaling pathway allows the study of numerous strategies to suppress STAT3 activation such as inhibiting the receptor ligand complexes, blocking the kinases that phosphorylate the cytoplasmic tail of the receptor, inducing the activity of the phosphatases that dephosphorylate STAT3, inhibiting JAK kinases thereby stopping STAT3 dimerization, preventing nuclear translocation of STAT3, blocking STAT3 DNA binding and transcriptional activity and application of STAT3 anti-sense strategies and decoy oligodeoxynucleotides [14,42]. Moreover, DNA-alkylating agents that are platinum complexes, such as cisplatin, are extensively used in chemotherapy and STAT3 was observed to be inhibited by cisplatin. In particular, Turkson et al. [43] generated a platinum (IV)based compound, CPA-7, which was found to inhibit STAT3 at low micromolar concentrations. A second compound based on the same principle, IS3 295, decreased expression of cyclin D1 and Bcl-xL and induced cell-growth arrest at $G_{0} / G_{1}$ phase and apoptosis of tumor cells [44]. Meydan et al. [45] demonstrated that inhibition of JAK2 activity by a tyrosine kinase (TK) blocker, AG-490, selectively blocked leukemic cell growth in vitro and in vivo by inducing programmed cell death. Several studies have also established inhibition of STAT3 phosphorylation by pharmacological JAK2 blocker, AG-490 which resulted in inhibition of the growth of tumor cells due to induction of apoptosis [46]. Furthermore, the use of monoclonal antibodies against IL-6 is a promising strategy to combat STAT3 signaling pathway. In particular, Sant7, a potent IL-6 antagonist, has been tested in the human multiple myeloma cell line, U266, and was shown to block IL-6 receptor signaling by inhibiting STAT3 activation, thereby inducing apoptosis [47].

In the present review, we discuss firstly the possible role of STAT3 signaling cascade in the initiation/development of several cancers and also analyze the role of various STAT3-regulated genes in cancer progression, inflammation, survival, invasion, metastasis, and angiogenesis. Also, we have critically analyzed the role of few important synthetic and natural blockers of STAT3 activation that have exhibited significant anticancer effects in tumor cell lines, preclinical models and clinical samples in the last few years.

\section{STAT3 activation by diverse agents}

The STAT signaling pathway was originally discovered in the context of normal cytokine signaling. STAT3 activation by phosphorylation is a highly regulated and transient process. More than 40 different polypeptide ligands cause STAT phosphorylation. STAT3 is activated in response to many cytokines such as IL-6 [48], leukemia inhibitory factor (LIF) [49], cardiotrophin-1 [50], ciliary neurotrophic factor (CNTF) [51], IL-5 [52], IL-9 [53], IL-10 [54], IL-11 [55], IL-12 [56], IL-21 [57], IL-22 [58], IL-27 [59], IFN- $\gamma$ [60], TNF- $\alpha$ [61], LIGHT, a member of the TNF superfamily [62], monocyte chemotactic protein-1 (MCP-1) [63], macrophage inflammatory protein-1 $\alpha$ (MIP$1 \alpha$ ) [64], CCL-5/RANTES [64], stem cell factor (SCF) [65], oncostatin M (OSM) [66]), growth factors (e.g., EGF [67], TGF $\alpha$ [61], PDGF [68], IGF1 [69], G-CSF [70], M-CSF [71] and GM-CSF [52]) and oncogenic proteins through phosphorylation of tyrosine 705 . In addition, numerous carcinogens (e.g. nicotine in cigarette smoke [34], diesel exhaust particles [72], hepatitis C virus core protein [73], lipopolysaccharide (LPS) [74]), environmental stress (e.g., ultraviolet light [75], osmotic shock [76], heat shock [77] and oxidative stress [78]) and other factors such as EBV oncoprotein LMP1 [79], HIV-1 Nef protein [80], leptin [81], $\mathrm{Ca}^{2+} /$ calmodulin-dependent protein kinase II $\gamma$ (CaMKII $\gamma$ ) [82], bile acids and low $\mathrm{pH}$ [83], black soy peptides [84], diazoxide [85], isoliquiritigenin [86], and olanzapine [87] have been identified to activate STAT3 (Fig. 1).

The growth factor receptors that are known to cause the activation of STAT3 include epidermal growth factor receptors (EGFRs), fibroblast growth factor receptors (FGFRs), insulin-like growth factor receptors (IGFRs), hepatocyte growth factor receptors (HGFRs), platelet-derived growth factor receptors (PDGFRs), and vascular endothelial growth factor receptors (VEGFRs) [88]. The binding of growth factors to the corresponding receptor leads to specific phosphorylation of receptor tyrosine residues to create docking sites for the recruitment of latent cytoplasmic STAT3 through its SH-2 domain. The binding of STAT3 at receptor phosphotyrosine sites leads to the phosphorylation of tyrosine 705 in the C-terminal domain of STAT3, and this phosphorylation activates STAT3 [89]. Other classes of non-receptor protein tyrosine kinases have also been reported to stimulate STAT3 activation. Src family of kinases (SFKs) that include Src, Lck, Hck, Lyn, Fyn, and Fgr can either activate STAT3 directly or may function downstream of the activation of RTKs or GPCRs $[90,91]$. Receptors lacking intrinsic tyrosine-kinase activity recruit receptor-associated tyrosine kinases, such as JAK and Src upon ligand engagement, leading to STAT3 phosphorylation via the tyrosine phosphorylation cascade. In transformed cells, STAT3 can also be directly activated by constitutively active non-receptor tyrosine kinases, such as Src [92]. Tyr705 phosphorylation converts STAT3 from an inactive form to an active form, which undergoes dimerization via the interaction between the phospho-Tyr705 within one monomer and the $\mathrm{SH} 2$ domain within the other.

STAT3-mediated signaling is typically transmitted through the formation of Tyr705 phosphorylated canonical STAT3 homodimers. But in immune cells, the complex cytokine signaling required for generating a robust and specialized immune response is mediated through the use of limited number of STAT molecules, which involves the heterodimerization of STAT proteins [93]. STAT heterodimers has also been shown to be important in GM- and M-CSF signaling. While M-CSF was known to activate both STAT3 and STAT5, STAT5 homodimers as well as STAT3:STAT5 heterodimers could be formed upon M-CSF stimulation, but only STAT3:STAT5 heterodimers could bind to particular consensus sequences [94]. The IL-6 superfamily of cytokines also utilizes STAT heterodimerization, in response to IL-6, STAT3 can utilize STAT1:STAT3 heterodimers, especially in late phase of signaling cascade [95]. IL-27, which uses the IL-6 receptor subunit gp130 to induce STAT1 and STAT3 activation cascade, was also shown to form STAT1:STAT3 heterodimers, although the molecular consequences of that heterodimer are still not clear [96].

These homo-or hetero STAT3 dimers then dissociate from the receptor and translocate to the cell nucleus. Importin $\alpha 5 / \mathrm{NPI}-1$ mediates the nuclear transport of STAT3 [97] and has a STAT3-binding domain in C terminus. In the nucleus, STAT3 dimer binds to DNA, in particular, four loops per monomer contact the sugar-phosphate backbones of both DNA strands and recognize bases in the major groove where they bind to specific DNA response elements such as the IFN-stimulated response element (ISRE) present in the promoter regions of responsive target genes that are involved in cell proliferation, differentiation, and apoptosis to regulate their transcription. The STAT dimers recognize an 8- to 10-base pair inverted repeat DNA element with a consensus sequence of 5-TT(N)AA-3 [20].

Phosphorylation of a single serine (Ser727) in the C-terminal transactivation domain of STAT3 by numerous serine kinases including mTOR [98], protein kinase C delta (PKC) [99], CDK5 [100], and PKC- $\varepsilon$ [101] allows for the maximal activation of transcription of responsive genes [102]. The transcriptional activation by STAT3 proteins requires the recruitment of co-activators such as CBP (CREB-binding Protein)/p300, APE1/Ref-1 [103], and NCOA/Src1a [104]. During cytokine-mediated STAT3 activation, besides phosphorylation on tyrosine and serine sites within the carboxyl-terminal region, STAT3 is also acetylated on a single lysine residue 685 by histone acetyltransferase p300 [105], which was found to be critical for the formation of stable dimers.

In addition, latent or non-phosphorylated STAT dimers have been observed and appear to play a vital role in various aspects of cell signaling. Unlike other STATs, STAT3 can enter the nucleus independent of its phosphorylation, while activated STATs shuttle more rapidly than non-activated ones [20]. The high-resolution structures of 


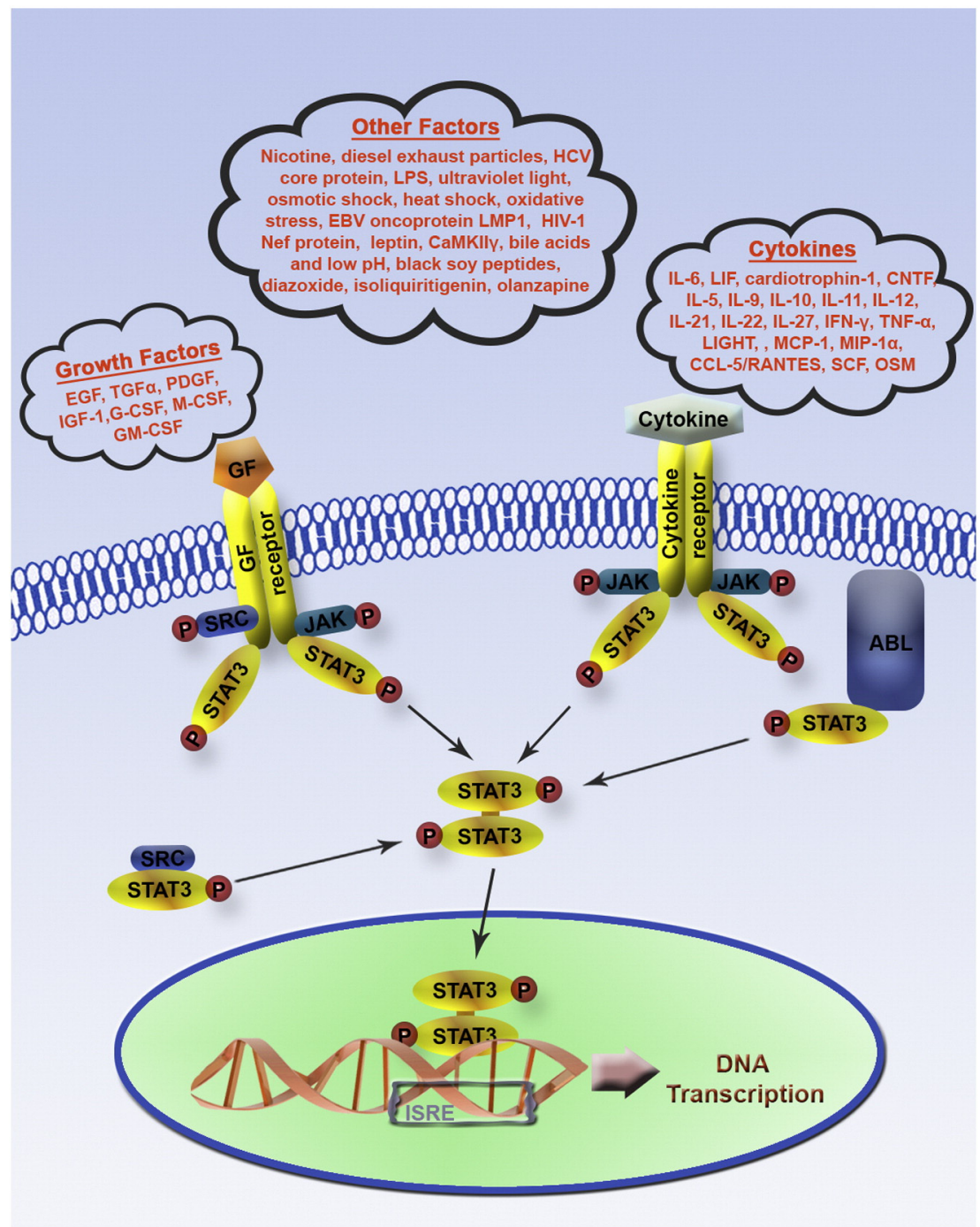

Fig. 1. Activation of STAT3 signal transduction cascade by distinct stimuli such as growth factors, cytokines and other extrinsic agents.

DNA-bound STATs 1 [106] and 3 [93] indicate that the mutual binding of two STAT monomers is possible without SH2-phosphotyrosine interactions. Importantly, these latent STAT dimers have been shown to have distinct transcriptional targets than their phosphorylated counterparts [107]. These homodimeric interactions require the $\mathrm{N}$-terminal domain, and are independent of the phosphotyrosyl-SH2 interactions that occur at the $\mathrm{C}$ terminus of the protein [93].

In normal cells, STAT3 activation is strictly controlled to prevent unscheduled gene regulation. Under physiological conditions, both the amplitude and duration of receptor-induced STAT3 activation is a tightly controlled transient process, peak STAT3 phosphorylation occurs within 15-60 min of exposure to cytokine, and even in the presence of continuous cytokine, STAT3 activation decreases over several hours [20]. The process is tightly controlled by several negative protein modulators, including the family of suppressor of cytokine signaling proteins (SOCS) 1-7 and CIS, the protein inhibitors of activated STATs (PIAS), several protein tyrosine phosphatases (PTPs), including SHP-2, PTP1B, PTPEC, TC45, SHP-1 and the ubiquitination-dependent proteosomal degradation systems [108]. Apart from the transcriptional promotion of target genes, STAT3 also plays a role in transcriptional suppression. Co-operation between STAT3 and c-Jun results in downregulation of Fas/CD95 transcription as well as Fas surface expression, which may be mediated by PI3K-AKT signaling [109].

\section{Role of STAT3 in tumorigenesis}

Among all STAT family members, STAT3 is most often correlated to tumorigenesis, and is considered as an oncogene [110] as it is the point of convergence of many signaling pathways triggered by cytokines, growth factors and oncogenes. Accumulating evidence strongly implicates the critical role of aberrant STAT3 activation in malignant transformation and tumorigenesis. Among the earliest clues that STATs contribute to oncogenesis were the findings that STAT3 is constitutively activated in Src-transformed cell lines and that interrupting STAT3 signaling blocks the transformation of mouse fibroblasts by the Src oncoprotein [111]. The first direct links between STATs and human cancer came from the findings that constitutive STAT3 activity is required for the growth of head and neck cancer [112] and of acute myelocytic leukemia and chronic myelocytic leukemia cells [113].

In contrast to the transient nature of STAT3 activation in normal cells, persistent activation of STAT3 has been reported in a variety of human tumor cell lines and primary human tumors, including leukemias, lymphomas [114], multiple myeloma [115], glioma [116], melanoma [117], head and neck [112], breast [118], ovarian [119], endometrial [120], cervical [120], colon [121], pancreatic [122], lung [123], brain [124], renal [125], and prostate [126] cancers. This increased level of 
phosphorylated STAT3 is not due to mutations in STAT3 but arises from oversupply of growth factors, such as TGF $\alpha$ or (IL6-family) cytokines within the tumor microenvironment that activate STAT3 in a paracrine manner. The activation of oncogenes, inactivation of tumor-suppressor genes, chromosomal rearrangement/amplification, deregulation of multiple potential upstream inputs such as elevated EGFR expression levels, EGFR mutations that result in constitutive RTK activation, overexpression of Src or other SFKs, mutations that hyperactivate JAKs [89] and other genetic events in neoplastic cells directly trigger STAT3 activation or the release of inflammatory mediators as part of an autocrine pathway [127]. Hyper-activation of STAT3 can also result from impairment mutations in any of the negative regulatory proteins, which limit the extent of STAT3 activation in normal cells [128]. For example, epigenetic silencing of SOCS3 by hypermethylation in CPG islands of the functional SOCS-3 promoter in human lung cancers [129] as well as mutations in STAT3-inactivating receptor protein tyrosine phosphatase delta in glioblastoma and other human cancers [130] leads to STAT3-mediated cell proliferation and survival.

Forced expression of a constitutively active form of STAT3 in mouse epidermis was found to shorten latency and enhance the number of malignant skin lesions progressing rapidly to squamous-cell carcinoma, induced by two-stage carcinogenesis [131]. Transfection of a dominantnegative form of STAT3 led to production of soluble factors that induce apoptosis and cell cycle arrest in the murine melanoma model [132]. A growth promoting role for STAT3 in the mouse model of anaplastic large cell lymphomas mediated by the oncogenic fusion protein, nucleophosmin-anaplastic lymphoma kinase (NPM-ALK), was demonstrated in both in vitro and in vivo models. Even though NPM-ALKdependent tumor could develop in the absence of STAT3, STAT3 is required for the growth and survival of NPM-ALK lymphoma T cells in vitro and in vivo. Ablation of STAT3 in mice bearing xenografted NPM-ALK-dependent T-cell lymphomas significantly impaired tumor growth in vivo [133], suggesting that tumor cells formed in the presence of STAT3 become STAT3 addicted. Moreover the growth of murine B16 melanoma cells that harbored activated STAT3 could be suppressed efficiently in mice by introduction of a functionally deficient STAT3 variant [134]. Constitutive activation of STAT3 is involved in many cellular processes including proliferation, survival, inflammation, invasion, metastasis and angiogenesis, all of which favor tumor initiation and progression (Fig. 2) and have been discussed below in detail.

\subsection{Proliferation}

STAT proteins have been shown to play important roles in cell proliferation induced by cytokines. The first evidence towards the role of STAT3 in survival was that STAT3 activation is essential for gp130-induced proliferation of the IL-3-dependent pro-B hematopoietic cell line, BAF/B03 cells [135]. In breast carcinoma cells, autocrinemediated STAT3 activation was found to correlate with cell proliferation [136]. Activated STAT3 promotes proliferation primarily by stimulating transcription of key cancer genes linked with proliferation of tumor cells, such as cyclin D1, cyclin B and cdc2, which are involved in the regulation of cell cycle [127]. The active form of STAT3 was found to promote the $G_{1} / S$ phase transition of the cell cycle through the expression of cyclin D1, which can associate with cdk4 or cdk6 and control progression from $G_{1}$ to $S$ phase in gastric [137] and colorectal [138] cancer cells. STAT3 was found to be phosphorylated in 19\% of bladder cancer tissues as well as several bladder cancer cell lines. Targeting the STAT3 signaling pathway in bladder cancer cells using an adenovirus-mediated dominant-negative STAT3 prohibited cell growth and induction of apoptosis in bladder cancer cell lines through downregulation of cell cycle-regulating gene cyclin D1 [139]. In human head and neck squamous cell carcinoma, constitutive activation of STAT3 was found to play a causative role in over-expression of cyclin D1, and in clinical studies, STAT3 activation level provided a novel prognostic factor [140]. Cucurbitacin I-mediated inhibition of STAT3induced cell-cycle arrest at the $\mathrm{G}_{2} / \mathrm{M}$ transition in cell lines derived from laryngeal squamous cell carcinoma and glioblastoma was associated with the downregulation of cyclin B1 and cdc2 [138]. Constitutively phosphorylated STAT3 has been found to induce over-expression of target genes such as cdc2, cyclin B1, m-ras, and E2F-1 in colon and breast carcinomas. E2F-1 is a transcription factor that activates the synthesis of mRNAs encoding proteins needed during the cell cycle. The products of some E2F-1-regulated genes, such as cyclin D1 and cyclin E, cdc2 and

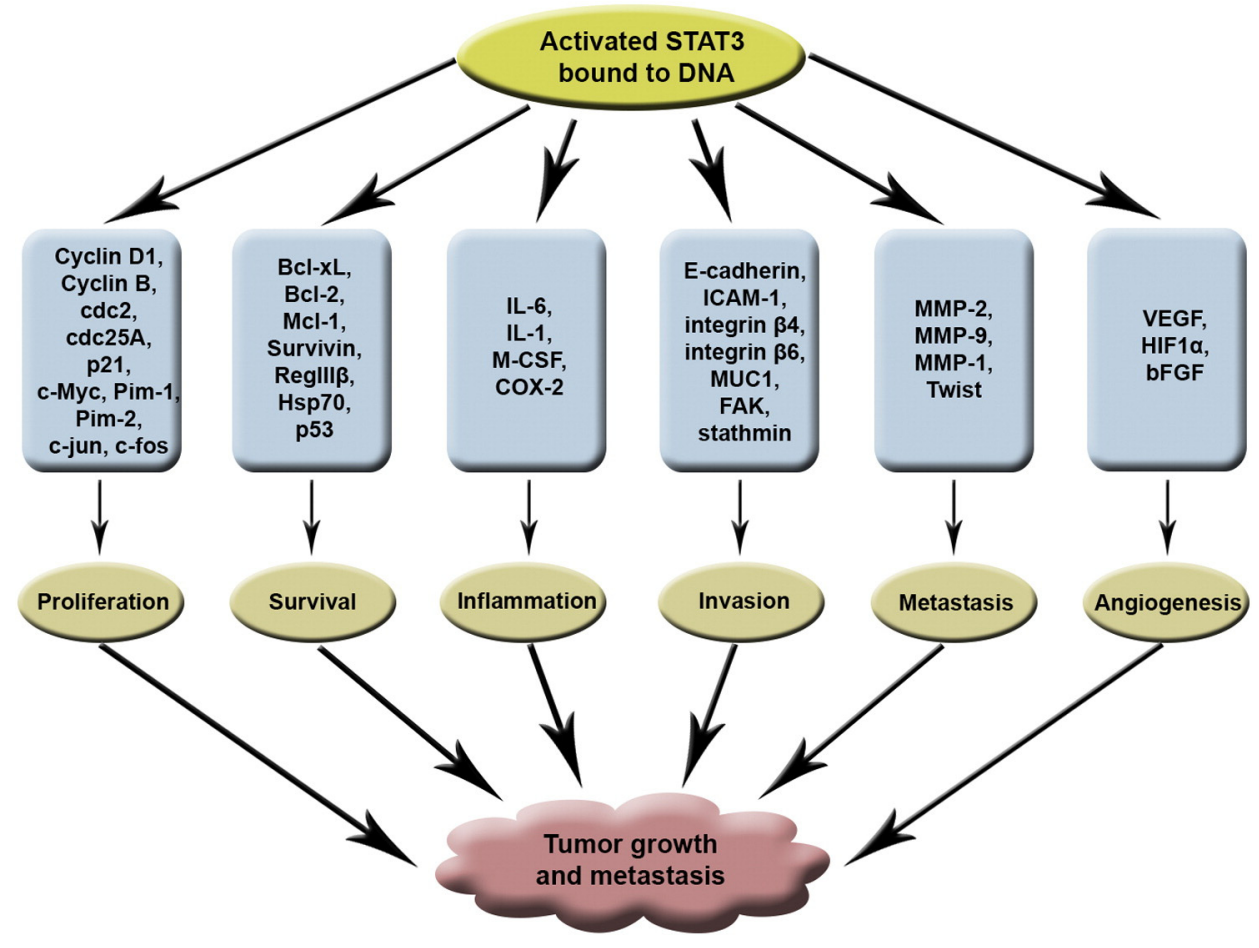

Fig. 2. Multifaceted role of STAT3 in tumor invasion and metastasis. 
cyclin B1 contribute to the $\mathrm{G}_{1} / \mathrm{S}$ and $\mathrm{G}_{2} / \mathrm{M}$ transitions and inhibit apoptosis [141]. STAT3 plays a key role in the $\mathrm{G}_{1}$ to $S$ phase cell-cycle transition induced by the cytokine receptor subunit gp130 through the upregulation of cyclins D2, D3 and A, and cdc25A, and the concomitant downregulation of $\mathrm{p} 21$ and $\mathrm{p} 27$. The membrane-proximal region of gp130, consisting of 133 amino acid residues, contains Tyr767, which is required for the activation of STAT3. The repression of p21 is controlled by several signaling molecules whose expressions are regulated by STAT3. For example, stimulation by gp 130 scarcely induced p21 expression in BAF-B03 (G133-bcl2 cells) consistent with the fact that gp130 induces growth. However, the truncated gp130 containing only the membrane-proximal 68 amino acid residues (G68-bcl2) could induce p21 mRNA. The same was true for the cells expressing gp130 mutated at Tyr767 or expressing dominant-negative STAT3s. These observations indicate that the region of gp130 consisting of the membrane-proximal 68 amino acid residues can induce p21 expression, and that suppression of STAT3 activity leads to gp130-induced gene expression of p21 through the membrane-proximal region [142].

In normal tissues, cell proliferation is controlled by irreversible entry into post-mitotic, differentiated states. Emergent tumor cells must escape this terminal differentiation, which in part is regulated by c-Myc [143]. The gp130-mediated STAT3 signaling has been shown to up-regulate the expression of several growth-promoting genes, such as c-Myc, Pim-1 and Pim-2 [144]. STAT3-C (constitutively dimerized and active form of STAT3) transformed cells were found to have 3- to 5-fold elevated levels of cyclin D1 mRNA and c-myc mRNA when compared to untransformed cells [110]. Inhibition of STAT3 with the orally active JAK inhibitor, AZD1480, was found to decrease tumor growth in neuroblastoma and pediatric sarcomas through downregulation of cell cycle regulators, cyclin D1, cyclin D3 and cdc25A, anti-apoptotic genes $\mathrm{Bcl}-2$ and survivin, the metastasis-related factor TIMP-1, and c-Myc. Knockdown of STAT3 expression by RNAi inhibited the growth of human ovarian cancer through downregulation of cyclin D1, c-Myc and Bcl-2 [145].

\subsection{Survival}

STAT3 contributes to the tumorigenic process mainly by triggering pro-survival and pro-proliferative signaling into cells. Apoptosis is essential for the maintenance of normal physiological functions, as cell death occurs during natural elimination of aging cells and in immunoselection of $\mathrm{T}$ and $\mathrm{B}$ cells. One of the major characteristics of tumor cells is the ability to avoid programmed cell death. The $\mathrm{Bcl}-2$ family of proteins has been identified as important regulators of apoptotic cell death in many cell types, and aberrant expression of Bcl-2 family members is frequently found in diverse malignancies. One of the first indications that STAT3 signaling contributes to malignancy by preventing apoptosis pathway came from studies in multiple myeloma cells showing that increased expression of Bcl-xL, a member of the anti-apoptotic Bcl-2-family, is dependent on constitutively activated STAT3 [111]. Several anti-apoptotic proteins, such as survivin and members of the Bcl family (Bcl-xL, Bcl-2 and Mcl-1), which are known to be crucial for tumor cell survival, are direct target genes of STAT3 and are down-regulated as a consequence of STAT3 inhibition [146]. STAT3 has also been found to be involved in colorectal cancer cell growth, survival, invasion, and migration through regulation of gene expression, such as Bcl-2, p21waf1/cip1, p27kip1, E-cadherin, VEGF, and MMPs [147].

Multiple myeloma is a disease characterized by slow-growing plasma cells in which IL-6 is an important growth and survival factor. STAT3 is constitutively activated in bone marrow mononuclear cells from patients with myeloma, and in the IL-6-dependent human myeloma cell line, U266. Moreover, U266 cells are inherently resistant to Fas-mediated apoptosis and express high levels of the antiapoptotic protein, Bcl-xL. Blocking IL-6 receptor signaling from Janus kinases to the STAT3 protein inhibits Bcl-xL expression and induces apoptosis, demonstrating that STAT3 signaling is essential for the survival of myeloma tumor cells [113]. STAT3 activation is also involved in IL-6-dependent T-cell proliferation through prevention of apoptosis, independently of Bcl-2 [148]. In epithelial cells, STAT3 induces C-type lectin, RegIII $\beta$; that indirectly suppresses apoptosis, which is overexpressed in human colon cancer and inflammatory bowel disease [127]. Moreover, STAT3 was shown to repress transcription of murine p53 expression, thus impacting p53-mediated apoptosis and contributing to cell survival.

Mcl-1 is another anti-apoptotic gene of the Bcl-2 family that is a target of STAT3. Blocking STAT3 in human tumor cells has been shown to down-regulate Mcl-1 expression and induce tumor-cell apoptosis [111]. Survivin, a member of the small inhibitor of apoptosis (IAP) family, has a bi-functional role by counteracting apoptosis as well as by controlling mitogenic progression. Survivin is selectively expressed during $\mathrm{G}_{2} / \mathrm{M}$ transition, localizes to mitotic spindle microtubules, and is phosphorylated by physical association with cdc2 [138]. STAT3 was constitutively activated in various human gastric cancer cells and its inhibition by ectopic dominant-negative STAT3 or Janus kinase inhibitor was found to induce apoptosis. Furthermore, STAT3 inhibition markedly decreased survivin expression, while forced expression of survivin rescued human gastric adenocarcinoma AGS cells from apoptosis induced by STAT3 inhibition [137].

The proliferative effect of STAT3 in tumor cells is mediated indirectly through the downregulation of pro-apoptotic factors such as Fas. The expression of dominant negative STAT3 or c-Jun in melanoma cells was found to increase Fas expression efficiently [149]. Decreased Fas expression during tumor progression often results in a loss of Fas-ligand-mediated apoptosis and enables the progression of cells through division. Activated STAT3 is also involved in the induction of the immediate early genes c-jun and c-fos and repression of the cell cycle inhibitor p21 [127]. A positive correlation has been observed between the expression of p-STAT3 and c-jun in hepatocellular carcinomas (HCC) and their surrounding liver tissues [150]. STAT3 was found to regulate the hepatocyte growth factor induced proliferation of human endothelial cells through activation of the c-fos promoter [151]. p21 is known to induce $\mathrm{G}_{2} / \mathrm{M}$ phase arrest by inhibiting cyclin-B/cdc2. siRNA-mediated inhibition of STAT3 in human colorectal cancer cell lines induced p16-, p21- and p27-mediated cell cycle arrest and apoptosis. STAT3 inhibition in gastric cancer cells down-regulated the expression of S-phase kinase-associated protein-2 (Skp2), which catalyzes the ubiquitination of p21, thereby reducing the ability of cells to migrate and invade, by inhibiting the activity of RhoA, downregulation of pFAK ( phosphorylated focal adhesion kinase) expression, upregulation of E-cadherin, and reducing the activities of matrix metalloproteinase-2 (MMP-2) and MMP-9 [152].

Heat shock protein 70 (Hsp70) can protect cells from apoptosis by binding and modulating the activity of various pro- and antiapoptotic proteins at transcriptional and post-translational level. Hsp70 prevents JNK-induced phosphorylation and inhibition of Bcl-2 and $\mathrm{Bcl}-\mathrm{xL}$ anti-apoptotic proteins and promotes cell survival through the maintenance of mitochondria stability. STAT3 can bind to specific sequences at the Hsp70 promoter (5'-CTGGRA-3') and is responsible for Hsp70 synthesis in cancer cells, mediating the expression of antiapoptotic proteins [153].

\subsection{Inflammation}

STAT3 signaling is a major intrinsic pathway for cancer inflammation because it is often activated in tumor-associated immune and inflammatory cells as well as malignant cells and is capable of inducing a large number of genes that are crucial for inflammation including IL-6, $10,11,17,23$, CXCL12, and COX-2 [127]. STAT3 was initially discovered as an acute-phase response protein that selectively binds to the IL-6responsive element within the acute-phase gene promoter, thus suggesting its link to inflammation [88]. Cytokines, chemokines and other 
mediators, such as IL-6, IL-1 $\beta$, macrophage colony-stimulating factor, prostaglandins and cyclooxygenase- 2 (COX-2) are crucial for inducing and maintaining a cancer-promoting inflammatory environment, and STAT3 is crucial for regulating their expression [13]. Within the tumor microenvironment, the persistent activation of STAT3 in tumor cells leads to the production of cytokines, chemokines and growth factors which are released from them and the associated receptors which in turn activate STAT3 in stromal inflammatory cells and release inflammatory mediators to the microenvironment, thereby creating a loop.

Most of the pro-inflammatory agents have been shown to activate STAT3. IL-6 is a major mediator of inflammation, and its unchecked production leading to subsequent chronic inflammation exhibits a strong association with many types of cancer. IL-6 mediates its effects through the activation of the gp130/JAK/STAT3 pathway [48]. STAT3 induces the upregulation of sphingosine-1phosphate receptor-1 (S1PR1), which reciprocally activates STAT3, resulting in persistent IL-6 formation to drive tumor growth and metastasis in B16 melanoma and MB49 bladder cancer models [154]. IL-11 promotes chronic gastric inflammation and associated tumorigenesis in gastric epithelial cells mediated by and dependent on increased activation of STAT3 [55]. In non-small cell lung cancer, IL-6-induced STAT3 activation has been shown to be dependent on COX-2, a pro-inflammatory enzyme [155]. STAT3 can directly interact with nuclear factor, NF- $\kappa$ B family member RelA, through acetyltransferase p300-mediated acetylation, trapping it in the nucleus and thereby contributing to constitutive NF- $\kappa \mathrm{B}$ activation in tumor-associated hematopoietic cells and various malignancies [156]. LPS-mediated IL-1 $\beta$ and IL-6 production in murine macrophage cell lines and primary macrophages is dependent on STAT3 phosphorylation [157]. Overexpression of mutant STAT3C in alveolar type II epithelial cells of transgenic mice leads to severe pulmonary inflammation, including immune cell infiltration and upregulation of pro-inflammatory cytokines and chemokines in the lung, leading to spontaneous lung bronchoalveolar adenocarcinoma [158].

\subsection{Invasion}

STAT3 is involved in regulating cell movement, mainly by cytoskeleton reorganization and controlling cell adhesion properties. The first evidence for the role of STAT3 in cell migration was the observation that conditional disruption of STAT3 in keratinocytes resulted in impaired wound healing due to compromised migration in response to cytokines and growth factors, such as EGF, TGF $\alpha$, HGF and IL-6, both in vivo and in vitro [159]. Recent studies demonstrate enhanced STAT3 activation with increased cell-cell contact or increased confluence, indicating that STAT3 may serve as a sensor of tumor cell contact and up-regulate genes necessary for cell invasion and migration $[160,161]$. In lung epithelial cells, STAT3 regulates a common set of genes such as fibrinogen, lipopolysaccharidebinding protein (LBP), SOCS3, c/EBP, BCL6, JunB, Myc, CCL2, CXCL2, PAI-1, proteases in the cathepsin and SERPIN families such as uPA and its receptor uPAR, which are involved in wound healing and cancer cell invasion, migration and angiogenesis [162].

There was a negative correlation between the expression intensity of phosphorylated STAT3 and that of tumor suppressor gene Ecadherin in human cutaneous squamous cell carcinoma (SCC). The activation of STAT3 was closely related to the invasive potential of SCC, whereas E-cadherin suppression contributed to the invasive and metastatic behavior of malignant tumor cells [163]. Mucin-like glycoprotein episialin (MUC1) plays an important role in tumor invasion and metastasis by diminishing cellular adhesion and is highly over-produced by a number of human carcinomas. STAT3 controls the expression of the MUC1 gene, which can mediate tumor invasion [164]. Integrins are essential mediators of tumorigenesis, adhesion, and migration. STAT3 contributes to disruption of epithelial adhesion and polarity downstream of ErbB2-Integrin $\beta 4$ signaling, leading to promotion of mammary tumorigenesis [165]. The introduction of constitutively-activated mutated STAT3-C in prostate epithelial cells decreased E-cadherin levels, increased numbers of lamellipodia and stress fibers, and enhanced migratory capacity and tumor formation by inducing the expression of integrin $\beta 6$ and its ligand, fibronectin [166]. STAT3-mediated regulation of cell motility is not just through its canonical transcriptional activity but also through non-nuclear functions. For example, activated STAT3 in ovarian cancer cells is localized to focal adhesions where it directly interacts with active focal adhesion kinase and paxillin and functions in cancer cell motility. Furthermore, depletion of STAT3 by siRNA transfection reduced the motility of ovarian cancer cells in vitro [167]. Non-phosphorylated STAT3 present in the cytoplasm interacts with the microtubuledestabilizing protein, stathmin, by binding to the $\mathrm{COOH}$-terminal tubulin-interacting domain, inhibiting its microtubule destabilization activity resulting in enhanced microtubules polymerization and cell migration [168]. Intercellular adhesion molecule-1 (ICAM-1/CD54) is an inducible cell-surface glycoprotein that mediates adhesion-dependent cellular interactions, and its high expression correlates with increased tumor malignancy and invasiveness. It was observed that irradiation significantly elevated nuclear phospho-p65/phospho-STAT3 interaction in correlation with increased intercellular adhesion molecule-1 (ICAM1) and soluble-ICAM-1 levels, migration and invasion in human glioma cell lines [169].

\subsection{Metastasis}

Degradation and remodeling of the extracellular matrix (ECM) and basement membranes by proteolytic enzymes such as MMPs secreted by tumor cells play a major role in tumor invasion and metastasis. The STAT3 target genes include several members of the MMP family, which are known to contribute to tumor invasion, angiogenesis and metastasis. Excessive activation of STAT3 correlates with tumor invasion and metastasis in a variety of cancers and high level of phosphorylated STAT3 is a prominent feature in colon and gastric cancers associated with adverse outcomes [127]. The constitutively active mutated STAT3-C-mediated transformation of immortalized human mammary epithelial cells requires the activity of MMP-9 and there is a positive correlation between activated STAT3 and enhanced MMP-9 expression in primary breast cancer specimens [170]. STAT3 interacts with Fra-1/c-Jun and binds to the specific promoter region of MMP-9 gene, leading to transcriptional activation of MMP-9 in breast cancer cell lines [171]. In highly metastatic melanoma cells, STAT3 signaling pathway directly contributes to the over-expression of another MMP family member, MMP-2. STAT3 can directly bind to the promoter of MMP-2 gene and upregulate its expression. Blockade of activated STAT3 by dominantnegative STAT3 significantly suppressed MMP-2 expression and the invasiveness of tumor cells, inhibited tumor growth, and prevented metastasis in nude mice [172]. In response to EGF stimulation, activated STAT3 interacts with c-Jun and binds to the promoter region of MMP-1 to induce its transcription in bladder cancer cells. Expression of the dominant-negative STAT3 is sufficient to inhibit the constitutive and EGF-induced migration, invasion and tumor formation in human bladder carcinoma xenograft model [173]. STAT3 is aberrantly activated in colorectal carcinomas and immunohistological examination of tumor specimens showed a clear co-localization of MMP-1 and activated STAT3. Experimentally induced STAT3 activity enhanced both the level of MMP-1 mRNA and secreted MMP-1 enzymatic activity, linking STAT3 to malignant tumor progression in colorectal carcinomas [174].

Inhibition of STAT3 by specific anti-sense oligonucleotide reduced proliferation, induced apoptosis, decreased mobility, and impaired tumor angiogenesis of HCC cells in orthotopic models in athymic mice. The expression of STAT3 target genes, VEGF and MMP-2, was also reduced following STAT3 suppression and there was inhibition of tumor growth, local transmission, and lung metastasis, resulting in 
significantly prolonged survival of tumor-bearing mice [175]. Suppression of STAT3 activation by transfection with a dominantnegative STAT3 decreased brain metastasis of human melanoma cells in animal models and melanoma cell invasion in vitro and significantly affected the expression of bFGF, VEGF and MMP-2 in vivo and in vitro by transcriptionally regulating the promoter activity in human melanoma cells [176]. Activation of STAT3 by IL6 was also found to induce Twist expression in human breast cancer cells by binding to the second proximal STAT3-binding site on the human Twist promoter and activating its transcription. Inhibition of STAT3 by STAT3 small hairpin RNAs reduced migration and invasion of human breast cancer cells [177]. Twist is involved in tumor metastasis through the upregulation of MMP-2 and -9 [178] and inhibition of TIMP-1 [179]. Moreover, STAT3-deficient keratinocytes demonstrated increased cell adhesiveness and compromised growth factor-inducible cell migration, accompanied with an increased number of tyrosyl-hyperphosphorylated focal adhesion and tyrosine phosphorylation of p130cas, suggesting that STAT3 in keratinocytes plays a critical role in modulating cell adhesiveness to the substratum leading to growth factor-dependent cell migration [180].

\subsection{Angiogenesis}

The intrinsic ability of a cancer cell to proliferate uncontrollably and resist apoptosis is not sufficient for tumor development. Tumors cannot sustain their growth unless they are supplied with oxygen and nutrients from newly formed blood vessels. Activated oncogene products play a crucial role in stimulating angiogenesis. One of the most potent angiogenesis-inducing signals is VEGF. STAT3 is constitutively activated in glioma and medulloblastoma tumors and is considered to play a central role in autocrine activation of VEGF [124]. One of the earliest evidence to suggest that STAT3 is linked to angiogenesis was from granulocyte-macrophage colonystimulating factor-induced angiogenic activity in chick chorioallantoic membrane and GM-CSF induced vessel sprouting from chicken aorta rings [181]. Transfection of cells with the constitutively activated STAT3-C mutant was found to be sufficient to increase VEGF expression and induce angiogenesis in vivo [182]. Among the various pro-angiogenic factors, VEGF and hypoxia-inducible factor- $1 \alpha$ (HIF-1 $\alpha$ ) stand out as prominent transcriptional targets for STAT3, and a requirement for STAT3 has been proposed for functionality of HIF-1 $\alpha$ [127]. It was shown that human breast cancer, head and neck carcinoma, melanoma [182], pancreatic cancer [122] and cervical cancer cell lines [183] that display constitutively active STAT3 also express VEGF and that STAT3 activity up-regulates VEGF expression and tumor angiogenesis, suggesting that downmodulation of STAT3 activation can suppress the expression of VEGF and inhibit angiogenesis. Blocking STAT3 signaling has been shown to inhibit Src-mediated VEGF upregulation and a complete inhibition of VEGF-dependent vascular permeability of human tumor cells in vivo [184].

STAT3 activity in tumor-derived myeloid cells can up-regulate the expression of a number of known STAT3 target genes, including VEGF, bFGF, and MMP-9. VEGF and bFGF contribute to myeloid cell-mediated and STAT3-dependent angiogenesis. In addition, CCL2, CXCL2, and IL-1B, which can contribute to myeloid cell-mediated angiogenesis, required STAT3 for their elevated expression in tumor-derived myeloid cells, suggesting that STAT3 activity in immune cells can contribute to tumor angiogenesis at multiple levels [185]. Expression of phospho-STAT3 had a positive correlation with the VEGF and Bcl-2 in gastric cancer specimens, suggesting that phospho-STAT3 expression might be associated with angiogenesis, anti-apoptosis, and tumor progression in this particular cancer [186]. STAT3 signaling pathway activation was found to mediate tumor angiogenesis in non-small cell lung cancer by the upregulation of VEGF and bFGF. The expression of p-STAT3 in human samples correlated with VEGF and bFGF while knocking down STAT3 reduced the expression of VEGF and bFGF in human lung cancer cells [187].

Hypoxia-inducible factor $1 \alpha$ (HIF- $1 \alpha$ ) is a transcription factor that controls oxygen homeostasis and is the final switch for VEGF upregulation in cancer [188]. STAT3 can indirectly regulate VEGF by inducing the expression of HIF- $1 \alpha$, which drives VEGF transcription upon hypoxic stimulation. STAT3 is required for both basal and growth signal-induced expression of HIF- $1 \alpha$ and targeting STAT3 with small-molecule inhibitor blocks HIF- $1 \alpha$ and VEGF expression in vitro and inhibits tumor growth and angiogenesis in vivo [189]. Activated STAT3 in ischemic rat kidney and in hypoxic renal carcinoma cells increased the cellular levels of HIF- $1 \alpha$ either by blocking protein degradation or by enhancing HIF- $1 \alpha$ synthesis under hypoxic conditions. STAT3 also interacts directly with HIF-1 $\alpha$ and is recruited to the human VEGF promoter in response to hypoxia, suggesting that STAT3 is a target for hypoxia-induced angiogenesis in human renal carcinoma [190]. As constitutively active STAT3 can inhibit p53 expression by binding to the p53 promoter [191], interruption of STAT3 signaling may lower HIF- $1 \alpha$ activity by promoting its degradation through p53-dependent mechanisms. Thus, STAT3 inhibitors can block VEGF expression at several levels, generating a potent anti-angiogenic effect.

\section{Selected natural inhibitors of the STAT3 signaling pathway}

The main goal of using a target-specific drug is to inhibit a molecular target central to a disease mechanism of interest. The first step toward this goal is to identify individual molecular targets and validate their relevance to the human disease. This is followed in turn by identification of specific chemical-or antibody based small molecule modulators or inhibitors of the target [192]. In theory, targeting a single molecular mechanism should be sufficient to achieve a significant therapeutic effect; in reality, however, single-target drugs have had very little therapeutic impact. In fact, they have generally been highly ineffective in treating complex diseases (e.g., cancer) [193] or diseases affecting multiple tissues or cell types (e.g., diabetes and immunoinflammatory disorders). Drugs aimed at multiple targets can be more efficacious and less vulnerable to acquired resistance because the disease system is less able to compensate for the action of two or more drugs simultaneously. This multi-target approach can be particularly beneficial in cancers because oncogenesis is known to be a multigenic process [194]. For example, the ErbB2 (HER-2/neu) inhibitor trastuzumab (Herceptin) is now being combined with the anti-VEGF inhibitor bevacizumab (Avastin) to treat breast cancer.

As discussed above, aberrant activation of STAT3 plays a pivotal role in the initiation, progression and metastasis of different cancers and thereby the abrogation of STAT3 activation using pharmacological inhibitors can form the basis of future cancer therapy. However, interestingly, a number of strategies, including the use of anti-sense oligonucleotide targeting STAT3, synthetic drugs, small molecules derived from natural sources, and gene therapy techniques have been employed over the last decade to suppress deregulated STAT3 signaling cascade in cancer. In the following sections, we will discuss about selected natural and synthetic agents that have shown significant efficacy in blocking STAT3 activation and thereby inhibiting tumor growth and metastasis.

\subsection{Betulinic acid}

Betulinic acid (Fig. 3) is a pentacyclic triterpene, discovered in 1995 from the stem bark of the plant Zizyphus mauritiana and was initially reported to be a melanoma-specific cytotoxic agent [8]. In addition, numerous studies over the past decade showed that betulinic acid could induce apoptosis in thyroid, breast, lung and colon carcinomas, 


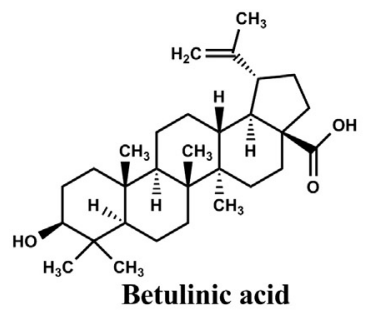<smiles>O=C(/C=C/c1ccc(O)c(O)c1)c1ccc(O)cc1O</smiles><smiles>O=C(O)/C=C/c1ccc(O)c(O)c1</smiles>

Caffeic acid<smiles>COc1ccc(CNC(=O)CCCCC=CC(C)C)cc1O</smiles>

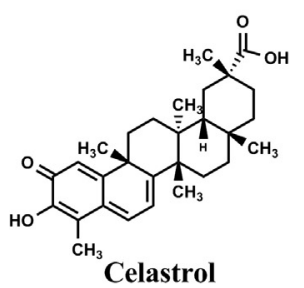

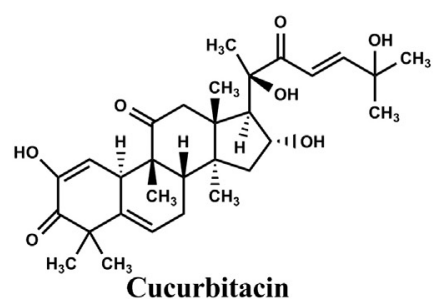<smiles>COc1cc(/C=C/C(=O)CC(=O)/C=C/c2ccc(O)c(O)c2)ccc1O</smiles>

Curcumin

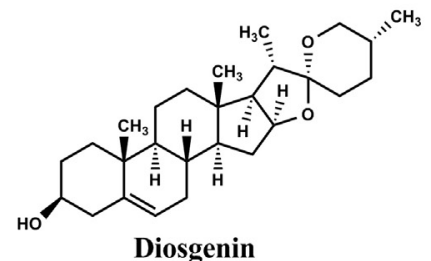<smiles>CC[C@]1(C)C(=O)C[C@H]2[C@@H]3CCC4=CC(=O)CC[C@]4(C)[C@H]3CC[C@]21C</smiles>

Guggelsterone<smiles>C=CCc1ccc(O)c(-c2ccc(O)c(CC=C)c2)c1</smiles><smiles>CC1=CC(=O)C(C(C)C)=CC1=O</smiles>

Thymoquinone<smiles>[O-]c1cc(O)cc(/C=C/c2ccc(O)cc2)c1</smiles>

Pterostilbene

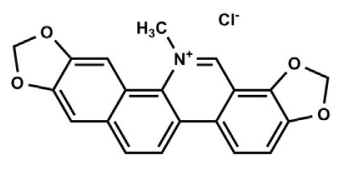

Sanguinarine

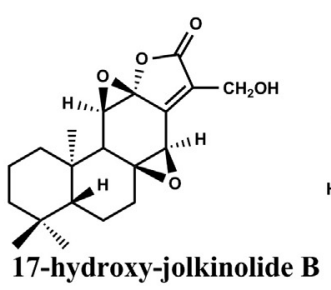

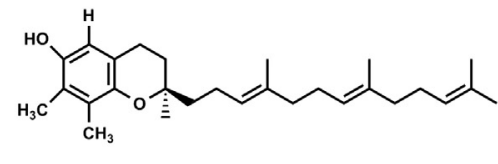

$\gamma$-Tocotrienol<smiles>NCCc1ccccc1</smiles>

Phenethyl isothiocyanate

Fig. 3. Chemical structures of selected natural blockers of STAT3 activation cascade

leukemias as well as multiple myeloma [8]. Pandey et al. [195] found that betulinic acid inhibited constitutive activation of STAT3, Src kinase, JAK1, and JAK2. Furthermore, betulinic acid induced the expression of the PTP SHP-1; silencing of the SHP-1 gene abolished the ability of betulinic acid to inhibit STAT3 activation. Betulinic acid also downregulated the expression of STAT3-regulated gene products, such as Bcl-xL, Bcl-2, cyclin D1, and survivin. It also induced apoptosis by an increase in the sub-G1 cell population and an increase in caspase-3induced PARP cleavage. Moreover, betulinic acid enhanced apoptosis in myeloma cells induced by thalidomide (from $10 \%$ to $55 \%$ ) and bortezomib (from 5\% to 70\%). Overall, the results suggest that betulinic acid down-regulates STAT3 activation through upregulation of SHP-1, suggesting the potential role of betulinic acid as a chemopreventive agent.

\subsection{Butein}

Butein (3,4,2,4-tetrahydroxychalcone) is derived from numerous plants including stem bark of Semecarpus anacardium, Rhus verniciflua Stokes, and the heartwood of Dalbergia odorifera [196]. Butein has been traditionally used for the treatment of pain, thrombotic disease, gastritis, stomach cancer, and parasitic infections in Korea, Japan, and China and so far no reports have suggested the toxicity of this polyphenol [3]. In Korea, butein is used as a food additive, thereby indicating that it is safe to be consumed by humans [197]. Reports have indicated that butein can suppress the proliferation of breast carcinoma, colon carcinoma, osteosarcoma, lymphoma, acute myelogenous leukemia, chronic myeloid leukemia, multiple myeloma, melanoma, and hepatic stellate cells [198-200]. Moreover, it was found to suppress phorbol 
ester-induced skin tumor formation [201,202], reduce antibodyassociated glomerulonephritis [203], and suppress liver fibrosis induced by carbon tetrachloride [204]. Furthermore, butein was also found to induce $\mathrm{G}_{2} / \mathrm{M}$ phase arrest and apoptosis in hepatocellular carcinoma (HCC) cells through reactive oxygen species (ROS) generation [205], suggesting that butein may have a great potential for HCC treatment. Additionally, its effects on HCC cell lines were investigated [206]. HCC cell lines HepG2 were incubated with different concentrations of butein for $6 \mathrm{~h}$, and the phosphorylation of STAT3 was examined by Western blot. It was observed that butein inhibited the constitutive activation of STAT3 in a dose-dependent manner, with maximum inhibition occurring at $50 \mu \mathrm{M}$. The inhibition of STAT3 was also timedependent, with maximum inhibition occurring at around 6 to $8 \mathrm{~h}$. Since butein induces the generation of ROS that blocks STAT3 signaling [205,207], it was next determined whether NAC, a ROS scavenger, could counteract the inhibitory effect of butein on STAT3 activation. HCC (HepG2) cells were pre-treated with NAC for $1 \mathrm{~h}$ before treatment with butein and it was observed that decrease in phosphorylated STAT3 was ROS-dependent, as levels reverted to control levels in the presence of NAC. Also, the phosphorylation of JAK2, which is constitutively active in HepG2 cells, was found to be suppressed in a timedependent manner upon butein treatment [206]. The expression of Bcl-2, a marker of cell survival was down-regulated and that of caspase-3, which is the marker of apoptosis was increased in the butein-treated cells compared with the control group. Overall, the results suggested that butein suppresses HCC growth through modulation of the STAT3 activation pathway. Further studies are required before its clinical potential is fully realized in HCC treatment.

\subsection{Caffeic acid}

Caffeic acid (CA) is a phenolic compound largely found in food plants [208]. CA has been extensively studied for its potent antioxidant [209,210] as well as anti-inflammatory properties [211]. Moreover, some caffeic acid derivatives, such as caffeic acid phenetyl ester (CAPE) have anti-oxidant properties that are similar to those of CA [212]. In addition, CA and CAPE were reported to inhibit NF- $\kappa B$ activation and iNOS expression [213] as well as inhibit angiogenesis, tumor invasion, and metastasis [214]. VEGF is known to play a crucial role in angiogenesis and tumor progression [215], and the inhibition of VEGF produced promising results as a tumor antiangiogenesis strategy in both animal models and cancer patients [216]. Hypoxia develops within solid tumors due to a mismatch between tumor cell proliferation, which is faster than the rate of blood vessel formation, thereby leading to a compromised tumor blood supply [217]. Moreover, hypoxia stimulates VEGF expression in tumors in order to promote angiogenesis to meet the metabolic requirement for growth. Recently, STAT3 was found to be a direct transcriptional activator of the VEGF gene, and demonstrated to up-regulate VEGF expression in various human cancers [218], suggesting that STAT3 activity may contribute significantly to overproduction of VEGF in tumors. Thus, it was considered that inhibiting STAT3 phosphorylation at Tyr705 might reduce VEGF expression in tumor cells. CA and its synthetic derivative, CADPE [3-(3,4-Dihydroxyphenyl)-acrylic acid 2-(3,4-dihydroxy-phenyl)-ethyl ester] were found to be actively involved in inhibiting STAT3 activity $[219,220]$. Since STAT3 phosphorylation at Tyr705 is essential for its nuclear translocation as well as for binding to specific promoter sequences on its target genes, the activities of CA and CADPE were investigated against STAT3 phosphorylation in vitro, using renal carcinoma Caki cells. It was noted that the phosphorylation of STAT3 at Tyr 705 increased in response to hypoxia and was decreased by CA or CADPE in a dosedependent manner. To study the inhibitory effects of CA and CADPE on hypoxia-induced STAT3 translocalization, wild-type STAT3 was transfected into COS7 (STAT3-deficient cell lines), which were then fractioned into nuclear and cytosolic proteins. The Western blot results showed that phosphorylated STAT3 was translocated from cytosol to the nucleus in response to hypoxia, but STAT3 remained in the cytoplasm of cells pre-treated with $100 \mu \mathrm{M}$ CA or $30 \mu \mathrm{M}$ CADPE. These results thus suggested that CA or CADPE inhibited STAT3 phosphorylation that was required for nuclear translocation of STAT3, and also inhibited the hypoxia-induced nuclear translocation of STAT3. The effects of CA or CADPE on suppression of VEGF expression were also studied. Firstly, luciferase assays were carried out in Caki-I cells using a VEGF promoter reporter plasmid. It was observed that hypoxia increased the reporter activity in Caki-I cells but not in cells pretreated with $100 \mu \mathrm{M}$ CA or $30 \mu \mathrm{M}$ CADPE. Subsequently, in cells transfected with STAT3-specific siRNA, the hypoxia-induced reporter activity of VEGF promoter was found to be significantly reduced by the siRNA-mediated repression of STAT3. Furthermore, in Caki-I cells pre-treated with CA or CADPE and thereafter subjected to hypoxia, the hypoxia-induced mRNA expression of VEGF decreased in a dosedependent manner. Thus, it can be concluded that CA or CADPE reduced hypoxia-induced transcriptional activity of VEGF by inhibiting STAT3, blocking STAT3 recruitment, and blocking the formation of a transcriptional unit between STAT3, HIF-1 $\alpha$, and p300 on VEGF promoter [215].

\subsection{Capsaicin}

Capsaicin (N-vanillyl-8-methyl-alpha-nonenamide) is a spicy component of hot pepper that induces certain cancer cells to undergo apoptosis. It has been reported to have a promising role in cancer chemoprevention [221]. Capsaicin has been reported to induce apoptosis in multiple myeloma cells through down-regulation of STAT3-regulated expression of Bcl-2, Bcl-xL, and survivin [222]. The effect of capsaicin on both constitutive and IL-6-induced STAT3 activation, STAT3-regulated gene products involved in proliferation, survival, and angiogenesis, was investigated in multiple myeloma cells. It was found that capsaicin inhibited constitutive activation of STAT3 in multiple myeloma cells in a dose- and time-dependent manner. Capsaicin also inhibited IL-6-induced STAT3 activation as well as the activation of JAK1 and c-Src. Moreover, pervanadate reversed the capsaicin-induced down-regulation of STAT3, suggesting the involvement of a protein tyrosine phosphatase. Capsaicin downregulated the expression of cyclin $\mathrm{D} 1, \mathrm{Bcl}-2, \mathrm{Bcl}-\mathrm{xL}$, survivin, and VEGF. Moreover, capsaicin induced the accumulation of cells in $G_{1}$ phase, inhibited proliferation, and induced apoptosis. Capsaicin also significantly potentiated the apoptotic effects of bortezomib and thalidomide in multiple myeloma cells. Upon administration of capsaicin, the growth of human multiple myeloma xenograft tumors in male athymic nu/nu mice was inhibited. These results collectively suggest that capsaicin is a novel blocker of the STAT3 activation pathway, with a potential role in the prevention and treatment of myeloma.

\subsection{Celastrol}

Celastrol derived from the Chinese medicinal plant Tripterygium wilfordii, has attracted great attention recently for its potent anticancer effects $[223,224]$. Celastrol has been documented to inhibit proliferation, induce apoptosis, and suppress invasion/migration and angiogenesis in a wide variety of tumor models both in vitro and in vivo [225]. Thus, Lu et al. [226] investigated the effects of celastrol on STAT3 activation in HCC cells and in a xenograft mouse model. C3A cells, a subclone of the hepatoma-derived HepG2 cell line, were incubated with different concentrations of celastrol for $6 \mathrm{~h}$ and Western blot was used to examine the phosphorylation of STAT3. It was shown that celastrol inhibited the constitutive activation of STAT3 in C3A cells in a dose-dependent manner with maximum inhibition occurring at $5 \mu \mathrm{M}$. Moreover, the inhibition induced by celastrol was found to be time-dependent, with maximum inhibition occurring at 4 to $6 \mathrm{~h}$. Because tyrosine phosphorylation causes the dimerization and nuclear 
translocation of STAT3 [227], the authors also determined the ability of celastrol to modulate the DNA-binding activity of STAT3 which causes gene expression. Upon analyzing the nuclear extracts prepared from C3A cells, it was shown that celastrol inhibited STAT3 DNA-binding activities in a time-dependent manner therefore suggesting that celastrol abrogates the DNA-binding ability of STAT3. The effects of celastrol on suppressing nuclear translocation of STAT3 in C3A cells was also determined, [228] and it was concluded that celastrol could indeed inhibit the translocation of STAT3 to the nucleus, thereby inhibiting the function of transcription factors. Furthermore, as it is well-known that IL-6 induces STAT3 phosphorylation [229] therefore, the authors determined whether celastrol could inhibit IL-6-induced STAT3 phosphorylation. In HUH-7 human hepatocarcinoma cells, IL-6 was found to induce phosphorylation of STAT3 as early as $5 \mathrm{~min}$, with maximum phosphorylation observed at 30 to $60 \mathrm{~min}$. IL-6 also induced phosphorylation of STAT3 in a dose-dependent manner with initial activation observed at a dose of $5 \mathrm{ng} / \mathrm{mL}$. In HUH-7 cells, IL-6-induced STAT3 and JAK2 phosphorylation were suppressed by celastrol in a time-dependent manner. STAT3 activation regulates the expression of various gene products involved in cell survival, proliferation, angiogenesis, and chemoresistance [230]. It was found that expression of cyclin D1, Bcl-2, Bcl-xL, survivin, Mcl-1, and VEGF decreased in a time-dependent manner upon treatment with celastrol, with maximum suppression observed at around $24 \mathrm{~h}$. Celastrol has been well tolerated with no toxicity in pre-clinical studies using various inflammatory diseases and cancer models [231,232]. However, celastrol has never been tested in humans before and hence its clinically relevant doses are not known yet. Thus, overall, the in vitro and in vivo experimental findings clearly indicate that the antiproliferative and pro-apoptotic effects of celastrol in HCC are due to the suppression of STAT3 activation and provide a platform to explore the potential of celastrol to overcome toxicity and enhance treatment efficacy for patients with HCC. Moreover, celastrol has been found to inhibit the proliferation and suppress the growth of prostate, gliomas and chronic myeloid leukemia xenografts in nude mice models [225,233]. Also, the ability of celastrol to modulate the expression of pro-inflammatory cytokines, adhesion molecules, potassium channels, NF- $\kappa \mathrm{B}$, transforming growth factor-activated kinase 1 (TAK1), CXCR4, VEGFR, proteasome and heat shock response has been reported $[224,225,234]$. In another study by Kannaiyan et al. [224], to investigate whether celastrol could suppress the proliferation and induce chemosensitization of multiple myeloma cells by interfering with STAT3 activation pathways, it was observed that celastrol inhibited the proliferation of multiple myeloma cell lines regardless of their sensitivity or resistance to bortezomib and other conventional chemotherapeutic drugs. Celastrol inhibited both the constitutive and IL-6induced activation of STAT3, which induced apoptosis leading to an increase in the accumulation of cells in the sub-G1 phase, and activation of caspase-3. This result indicates that future studies in animal models to establish the anti-cancer effects of celastrol in vivo are warranted.

\subsection{Cucurbitacins}

Cucurbitacins are essential herbs used in a large number of traditional Chinese medicines $[235,236]$ and have been shown to possess anti-inflammatory, anti-microbial, and anti-cancer activities [237]. Chemically, cucurbitacins are highly diverse and can be divided into twelve categories, ranging from cucurbitacins A-T [236,238]. Cucurbitacin B is found in many Cucurbitaceae species and is one of the most abundant forms of cucurbitacins [239]. It has significant anti-inflammatory activity and has been used to treat hepatitis [240]. Recently, it was reported that cucurbitacin B could inhibit the growth of numerous human cancer cell lines and tumor xenografts [241,242]. The inhibitory effect of cucurbitacin B on STAT3 was examined in leukemia cells. K562 cells, an immortalized myelogenous leukemia line, were treated with cucurbitacin B at doses ranging from $1 \mu \mathrm{M}$ to $50 \mu \mathrm{M}$,
Western blot analysis showed that cucurbitacin B $50 \mu \mathrm{M}$ for $4 \mathrm{~h}$ inhibited STAT3 activation [243]. Furthermore, treatment with curcubitacin B reduced the level of phosphorylated STAT3 and its downstream targets, such as cyclin B1 and Bcl-2, in human HCC cell lines [244].

\subsection{Curcumin}

Curcumin (diferuloylmethane) is a dietary spice and is the active compound of turmeric (Curcuma longa) [245]. This compound has been shown to modify the expression of inflammatory cytokines and enzymes, transcription factors, and gene products linked to cell survival, proliferation, invasion, and angiogenesis. Curcumin has been found to possess anti-proliferative and pro-apoptotic effects in a number of tumor cell lines in vitro [246]. In murine carcinoma models, curcumin has also been shown to reduce the number and size of tumors, and even ameliorate tumor-induced immunodepletion of the host [247]. Phase I clinical studies of curcumin have shown that this agent can be administered safely at oral doses of up to $8 \mathrm{~g}$ per day with no doselimiting toxicity [248]. A recent phase II study of curcumin has shown that this compound has useful biological activities in patients with pancreatic cancer [249]. Various approaches are being investigated to overcome the limitations of curcumin bioavailability, such as the synthesis of curcumin analogs and development of improved delivery platforms for the parent compound, such as liposomal, nanoparticulated, and phospholipid complex formulations of curcumin [250].

The anti-tumor effects of curcumin on CTCL cell lines (cutaneous T cell lymphoma-leukemia cells) and peripheral blood mononuclear cells (PBMCs) from Mycosis Fungoides/Sézary syndrome (MF/SS) patients with a high percentage of circulating tumor T-cells were examined. It was shown that constitutive activation of STAT3 contributed to oncogenesis by stimulating cell proliferation and preventing apoptosis in CTCL cell lines. Western blot was performed in order to determine whether STAT signaling was involved in curcumin-induced apoptosis. The results showed that expression levels of both STAT3 and phosphorylated STAT3 decreased by a range of $21-55 \%$ and $38-47 \%$, respectively, in CTCL cells compared with untreated controls. Moreover, mRNA expression levels of Bcl-2 decreased by $22-94 \%$, and protein and mRNA expression levels of survivin decreased by $11-95 \%$ compared with untreated controls. From these findings, it can be concluded that curcumin selectively induces apoptosis in CTCL cell lines and PBMCs of MF/SS patients.

Glioblastomas are known to be the most common and most deadly of primary brain tumors [251]. The anti-cancer effects of curcumin were evaluated on glioma cells were evaluated in vitro and in vivo using an immunocompetent orthotopic mouse model. Curcumin inhibited JAK1, JAK2, and STAT3 tyrosine-phosphorylation in a dose-dependent manner in murine glioma cell lines. Real-time RTPCR revealed that curcumin down-regulated the transcription of STAT3 target genes such as c-Myc, MMP-9, Snail, and Twist, and Ki67. In addition, curcumin suppressed cell proliferation by inducing a $G_{2} / M$ phase arrest in a dose-dependent manner.

In addition, in a report by Bharti et al. [252], it was demonstrated that curcumin, a pharmacologically safe agent in humans, inhibited IL-6-induced STAT3 phosphorylation and consequent STAT3 nuclear translocation. Whether curcumin affects the phosphorylation of other STAT proteins in U266 cells was investigated. Besides STAT3, it was found that U266 cells expressed STAT5. Curcumin had no effect on STAT5 phosphorylation, but inhibited the IFN- $\alpha$-induced STAT1 phosphorylation. The constitutive phosphorylation of STAT3 found in multiple myeloma U266 cells was also abrogated upon treatment with curcumin. Also, CD138 ${ }^{+}$cells obtained from the bone marrow of 22 myeloma patients were examined for STAT3 and NF- $\kappa B$ activation after exposure to $50 \mu \mathrm{M}$ curcumin for $2 \mathrm{~h}$ [115]. The results indicated that exposure to curcumin down-regulate STAT3 activation and survival of $\mathrm{CD} 138^{+}$cells derived from multiple myeloma patients. 


\subsection{Diosgenin}

Diosgenin is a steroid sapogenin obtained from fenugreek (Trigonella foenum graecum). Various studies have shown that diosgenin suppresses proliferation and induces apoptosis in a wide variety of cancer cells. Anti-proliferative effects of diosgenin are mediated through cell-cycle arrest, disruption of $\mathrm{Ca}^{2+}$ homeostasis, activation of $\mathrm{p} 53$, release of apoptosis-inducing factor, and modulation of caspase- 3 activity [253]. The effects of diosgenin on human HCC cell line, C3A were investigated. C3A cells were incubated with different concentrations of diosgenin for $6 \mathrm{~h}$, and the phosphorylation of STAT3 was examined [254]. Diosgenin inhibited the constitutive activation of STAT3 in C3A cells in a dose-dependent manner, with maximum inhibition occurring at around $100 \mu \mathrm{M}$. It was also shown that IL-6-induced STAT3 phosphorylation in HUH-7 cells was suppressed by diosgenin in a timedependent manner. Additionally, it was found that diosgenin suppressed the constitutive phosphorylation of JAK1 and JAK2 in a time-dependent manner. The expression of cyclin D1, Bcl-2, Bcl-xL, survivin, $\mathrm{Mcl}-1$, and the angiogenic gene product, VEGF, also decreased in a time-dependent manner, with maximum suppression observed at around $24 \mathrm{~h}$. Further in vivo studies with diosgenin either alone or along with existing chemotherapeutic drugs are needed to demonstrate the potential application of diosgenin for treatment of cancers.

\subsection{Guggulsterone}

Guggulsterone (GS) is derived from Commiphora mukul and is used to treat obesity, diabetes, hyperlipidemia, atherosclerosis, and osteoarthritis $[255,256]$. GS has also been shown to have potent anti-cancer potential due to its ability to suppress the proliferation of a wide variety of human tumor cell types, including leukemia, head and neck carcinoma, multiple myeloma, lung carcinoma, melanoma, breast carcinoma, prostate, and ovarian carcinoma [257,258]. A study by Ahn et al. [255] further demonstrated the effects of GS on constitutive STAT3 activation in multiple myeloma cells. It was found that GS inhibited the constitutive activation of STAT3 in U266 cells in a dose-dependent manner with maximum inhibition occurring at 10 to $25 \mu \mathrm{M}$. The inhibition was also time-dependent, with maximum inhibition occurring at $4 \mathrm{~h}$. Since tyrosine phosphorylation causes dimerization of STAT3 and its translocation to the nucleus, where it binds to DNA and regulates gene transcription, the question arose whether GS could suppress the DNA-binding activity of STAT3. The nuclear extracts prepared from U266 cells showed that GS decreased STAT3 DNAbinding activity in a dose- and time-dependent manner. Because IL-6 is a growth factor for multiple myeloma cells and induces STAT3 phosphorylation [259,260], it was also determined whether GS could inhibit IL-6-induced STAT3 phosphorylation in multiple myeloma cells pretreated with GS for $4 \mathrm{~h}$. Indeed, IL-6-induced STAT3 phosphorylation was suppressed. Because protein tyrosine phosphatases have been implicated in STAT3 activation [261], it was further determined whether GS could inhibit STAT3 tyrosine phosphorylation by activating protein tyrosine phosphatase (PTPase). Treatment of U266 cells with the tyrosine phosphatase inhibitor sodium pervanadate reversed the GS-induced inhibition of STAT3 activation. This suggests that tyrosine phosphatases are involved in GS-induced inhibition of STAT3 activation. STAT3 regulates cyclin D1 which is required for cell proliferation and for transition from G1 to S phase of the cell cycle [262]. It was shown that GS treatment suppressed the expression of cyclin D1 in a time-dependent manner. GS also down-regulated the expression of Bcl-2, Bcl-xL, and Mcl-1, and VEGF in a time-dependent manner [255]. Furthermore, a time-dependent activation of caspase- 3 upon GS treatment was also observed. Activation of downstream caspases led to the cleavage of PARP protein. Thus, these results clearly suggest that GS induces caspase-3-dependent apoptosis in U266 cells. In another study, a dose-dependent decrease in cell viability was observed in human head and neck squamous cell carcinoma (HNSCC) cell lines upon treatment with GS. GS was also observed to induce apoptosis and cell cycle arrest, inhibit invasion, and enhance the efficacy of erlotinib, cetuximab and cisplatin in HNSCC cell lines. HIF- $1 \alpha$ was also decreased in response to GS treatment. In a xenograft model of HNSCC, GS treatment resulted in increased apoptosis and decreased expression of STAT3. Therefore, these results suggest that the inhibition of STAT3 and HIF- $1 \alpha$ by GS provide a strong rationale for further clinical investigation of this compound in the treatment of HNSCC [263-265]. Moreover, the reported safety of GS [266] makes it a good candidate for complementary and preventive therapy.

\subsection{Honokiol}

Honokiol is a small molecular weight natural product and is the main active compound of Magnolia officinalis, which is widely known to ameliorate microbial infection, inflammation, and gastrointestinal disorder and is used in traditional Chinese medicinal systems [267]. The ability of honokiol to modulate constitutive STAT3 activation in HCC cells was investigated by Rajendran et al. [268]. HepG2 cells were incubated with different concentrations of honokiol for $6 \mathrm{~h}$, and the phosphorylation of STAT3 was examined by Western blot. The results showed that honokiol inhibited the constitutive activation of STAT3 in HepG2 cells in a dose-dependent manner, with maximum inhibition occurring at $50 \mu \mathrm{M}$. The inhibition of STAT3 was time-dependent, with complete inhibition occurring at $6 \mathrm{~h}$. Moreover, the analysis of nuclear extracts showed that honokiol inhibited STAT3-DNA binding activities in a time-dependent manner. In HUH-7 cells incubated with honokiol, IL-6-induced STAT3 and JAK2 phosphorylation was suppressed by honokiol in a time-dependent manner. Phosphorylation of JAK2 was suppressed in a time-dependent manner upon treatment of HepG2 cells with honokiol. It was observed that honokiol induced the expression of SHP-1 protein in HepG2 cells in a dose-dependent manner, with maximum expression at 25-50 $\mu \mathrm{M}$ [29]. This stimulation of SHP1 expression by honokiol correlated with the downregulation of constitutive STAT3 activation in HepG2 cells. The expression of the cell cycle regulator, cyclin D1, the anti-apoptotic proteins $\mathrm{Bcl}-2, \mathrm{Bcl}-\mathrm{xL}$, survivin, Mcl-1 and the angiogenic gene product VEGF decreased in a timedependent manner upon honokiol treatment, with maximum suppression observed at around $24 \mathrm{~h}$. Additionally, honokiol potentiated the apoptotic effect of doxorubicin and paclitaxel in HepG2 cells [269] i.e. treatment of cells with honokiol together with either doxorubicin or paclitaxel significantly enhanced the apoptotic effects of doxorubicin from $12 \%$ to $36 \%$ and of paclitaxel from $10 \%$ to $32 \%$.

\section{Synthetic blockers of STAT3 activation cascade}

As indicated earlier, the JAK/STAT signaling pathway is involved in the regulation of cell growth, differentiation, and apoptosis [270]. Persistently active STAT3 is found in a wide range of human cancer cell lines and tissues where it was found to stimulate cell proliferation, promote angiogenesis, mediate immune evasion, and confer increased resistance to apoptosis, thereby contributing to oncogenesis. Thus it can be suggested that anti-STAT3 inhibitors hold great potential as promising targets for anti-cancer therapy. All STAT proteins in mammals consist of six domains, as follows: N-domain (ND), coiled-coil, DNAbinding, linker, Src homology 2 (SH2), and transcriptional activation domain [271]. These inhibitors exert their pharmacological effects by diverse mechanisms such as blocking abnormally activated upstream kinases such as JAK and Src or directly suppressing the STAT3 phosphorylation [272]. Most of the currently available inhibitors act by preventing STAT3 tyrosine phosphorylation i.e. they directly bind to the SH2 domain of STAT3 and prevent tyrosine phosphorylation, protein dimerization, and transcriptional activity [273]. The ND of STAT3 is involved in many protein-protein interactions, such as the interaction of two STAT dimers on neighboring sites to form a more stable tetramer, the interaction of STAT3 with other transcription 
factors and co-factors leading to formation of enchanceosomes and the interaction with histone-modifier proteins to cause changes in chromatin structure [274,275]. Moreover, the ND is also involved in interaction with receptors and in the nuclear translocation of STATs [276]. The domains are about 130 residues long and contain eight helices, which comprise most of the NDs [106]. A number of targeted libraries of cell-permeable analogs of the STAT3 second helix have been synthesized and are found to be potent inhibitors of STAT3dependent cancer cell survival and growth. Cell-permeable derivatives of the STAT3 second helix were found to directly and specifically bind to STAT3. In addition, the inhibitors caused significant changes in the mitochondrial potential of cancer cells, leading to cell death. Thus, these compounds are promising drug candidates and have provided a better understanding of the crucial role of the ND in STAT3 function [277].

One approach to prevent STAT3 from promoting transcription would be to inhibit the tyrosine kinase activities of JAKs that activate STAT3; however, in most cancers, the inhibition of multiple kinase pathways has been found to be impractical [278-280]. Several smallmolecule JAK inhibitors (such as AG490, LS-104, INCB018424, and CEP-701) have been tested in tumor xenograft models and some clinical trials for cancer [280]. Both in vitro and in vivo, AG490 was recorded to inhibit JAK2 activity, thereby reducing activated STAT3 levels, blocking STAT3 DNA binding, and inhibiting the growth of cancer cells. Furthermore, LS-104, a closely related analogue of AG490, has progressed to phase II clinical trials for acute lymphoblastic leukemia [281]. INCB018424, a small-molecule inhibitor of both JAK1 and JAK2, suppresses levels of phosphorylated STAT3 in subjects with mutant and wild-type JAK2[282]. INCB018424 is observed to elicit a clinical benefit in myelofibrosis patients while producing mild myelosuppression in $10 \%$ of patients. In a phase II study of CEP-701, levels of phosphorylated STAT3 have been reported to decrease upon treatment with the drug [280]. In multiple myeloma, JAKs are persistently activated due to a constant stimulation by IL- 6 , which is produced in the bone marrow environment. INCB20 is a synthetic molecule that potently inhibits all members of the JAK family. Treatment of multiple myeloma cell lines and patient tumor cells with INCB20 resulted in a significant dose-dependent inhibition of IL-6-induced cell growth. INCB20 also abrogated the protective effect of IL- 6 against dexamethasone by blocking phosphorylation of SHP-2 and AKT. In a severe combined immunodeficient mice xenografted with INA-6 human multiple myeloma cells, INCB20 significantly delayed INA-6 tumor growth. These studies show that disruption of JAKs and downstream signaling pathways may inhibit myeloma cell growth and survival as well as overcome cytokine-mediated drug resistance, thereby providing the pre-clinical rationale for using JAK inhibitors as a novel therapeutic approach in multiple myeloma [283].

The Philadelphia chromosome (Ph1), created by the reciprocal translocation between chromosomes 9 and 22, contains a gene called $B c r-a b l$ that encoded for a fusion protein called bcr-abl, and is the hallmark of chronic myelogenous leukemia (CML). The tyrosine kinase activity of the bcr-abl protein is required for the transformation into CML [284]. STAT3 was found to be specifically activated by bcr-abl in a murine embryonic stem (ES) cell model and in primary $\mathrm{CD} 34^{+} \mathrm{CML}$ cells [285]. Bcr-abl substantially phosphorylated STAT3 at Ser727 residue and, to a lesser extent, Tyr705 residue in Bcr-abl expressing cell lines such as UT7-p210 (human megakaryoblastic leukemia cell line), MO7E-p210 (human megakaryoblastic leukemia cell line), and K562 (human chronic myelogenous leukemia cell line) and in primary CD34 ${ }^{+} \mathrm{CML}$ cells. Inhibition of Bcr-abl with imatinib mesylate led to a dose-dependent downregulation of total STAT3 protein and mRNA, thereby suggesting that Bcr-abl may also be involved in the transcriptional regulation of STAT3 [286].

A novel approach using peptide aptamers that inhibit EGFRmediated phosphorylation of STAT3 have also been identified in a modified yeast two-hybrid screen [287]. However, a drawback of peptide inhibitors is poor cell permeability and metabolic stability, thus prompting the search for peptidomimetics and small-molecule derivatives. Several small-molecule inhibitors have been identified through peptide- and peptidomimetic-inspired rational design including in silico computational approaches and in vitro high-throughput screening [38,39]. A non-peptide small molecule called Stattic selectively inhibits STAT3 by directly binding to the SH2 domain [288]. The SH2 domain of STAT3 is important for the activation of STAT3 and its nuclear translocation, which is inhibited by Stattic. In a study by Turkson et al. [43], cell lysates prepared upon treatment with $10 \mu \mathrm{M}$ of Stattic showed a 7.6-fold increase in the sub- $G_{1}$ population in the STAT3-dependent MDA-MB-231 human breast adenocarcinoma cells and a 14.4-fold increase in MDA-MB-435S human melanoma cells. In contrast, only a slight increase (1.7-fold) in the sub- $\mathrm{G}_{1}$ population was observed in the STAT3-independent MDA-MB-453 cells, suggesting the induction of apoptosis in a STAT3-dependent manner. Moreover, terminal deoxynucleotidyl transferase-mediated nick end labeling (TUNEL) assay revealed significant apoptosis in MDA-MB-435S cells after treatment with $10 \mu \mathrm{M}$ Stattic for $24 \mathrm{~h}$. To summarize, Stattic inhibits binding of tyrosine-phosphorylated peptide motif to the STAT3 SH2 domain and abrogates dimerization and DNA binding of STAT3. It potently suppresses STAT3 activation and nuclear translocation, and selectively induces apoptosis of STAT3-dependent cancer cell lines, thus making it a potentially useful tool for the inhibition of STAT3 activation.

Another strategy to block STAT3-protein interactions employs G-rich oligodeoxynucleotides that form potassium-dependent four-stranded structures (i.e., G quartets) to occupy sites within the STAT3 SH2 domains. Double-stranded oligodeoxynucleotides (dsODN) are designed and synthesized to mimic cis regulatory elements within genes that are activated by STAT3, which then compete for active STAT3 dimers and block induction of STAT3-responsive gene expression and tumor cell growth in vitro [39,287]. The inhibition of STAT3mediated transcription, elicited by daily intratumoral injections of a STAT3-specific dsODN decoy, has also been reported to reduce tumor cell growth in mouse xenograft models $[289,290]$. In a safety trial conducted in cynomolgus monkeys, intramuscular injection of $3.2 \mathrm{mg} / \mathrm{kg}$ of a STAT3 dsODN decoy produced no observable adverse effects despite reductions in STAT3 target gene expression at the site of injection [290]. Moreover, a sequence-specific RNA interference (RNAi) method to switch off constitutive STAT3 expression has also been studied. The most effective sequence of a synthetic small interfering RNA (siRNA) specific for STAT3 and its effect on suppression of the growth of oral squamous cell carcinoma cells has been investigated. Thus, targeting STAT3 using siRNA may represent a useful approach for the treatment of oral squamous cell carcinoma [291]. Furthermore, the platinum compounds appear to disrupt STAT3 DNA binding activity and reduce phosphotyrosine levels of STAT3 [292]. The fourth-generation platinum complex, CPA-1 and CPA-7, have been demonstrated to suppress tumor proliferation and metastasis [43]. In addition, CPA-1 and CPA-7 interfere with STAT3 and disrupt its ability to bind to DNA in breast carcinoma, mouse melanoma, prostate cancer and lung carcinoma cells. In a study by Liby et al. [293] myeloma and lung cancer cells were treated with the new synthetic triterpenoid, 2-cyano-3,12-dioxooleana1,9(11)-dien-28-oicacid (CDDO)-Imidazolide (CDDO-Im), and the effects on STAT3 phosphorylation and apoptosis were evaluated. It was reported that CDDO-Im suppressed constitutive or IL-6induced STAT3 phosphorylation in human myeloma and lung cancer cells within 30-60 min and at nanomolar levels. Furthermore, CDDOIm up-regulated critical inhibitors of STATs, such as suppressor of cytokine signaling- 1 and SH2-containing phosphatase-1. Thus, CDDOImidazolide is a potent suppressor of STAT signaling pathway and warrants further evaluation of the mechanistic basis for future clinical use to control inflammation or cell proliferation [293,294]. In conclusion, it can be observed that it is important to develop new drugs to control the activation of STAT signaling pathway, particularly their phosphorylation state, which is required for the gene expression. 


\section{Conclusion and perspectives}

STAT proteins were originally discovered in the context of normal cytokine signaling and were not considered as potential targets for cancer therapy at that time. Recent studies provide evidence for persistent STAT activation at high frequency in clinical tumor samples, so that STAT3 now emerges as an attractive target for tumor treatment. Persistent STAT3 activation in tumor cells seems to disrupt the normal physiological roles in controlling cell growth, survival, angiogenesis and immune function while conversely, blockade of STAT3 in cultured tumor cells was found to induce apoptosis, inhibit cell proliferation, suppress angiogenesis and stimulate immune responses. Inhibiting STAT3 at the source of activating signaling pathways would be challenging because healthy cells would also be affected, unless there is a way to accurately target only tumor cells. As STAT3 is activated by dimerization and then binds DNA to perform its functions, specific inhibitors targeting the disruption of their protein-protein interactions or DNAbinding activity, are more promising agents. Inhibitors may target upstream kinases, such as JAK2 or Src, or act as inducers of Src homology 2 phosphatases. After a decade of preclinical evaluation of STAT3 inhibitors, limited translational studies are currently in progress. The design and discovery of truly specific and potent STAT3 inhibitors is a challenging process. There is an abundance of natural compounds with inhibitory properties against this transcription factor that could act as lead compounds for the synthesis of more efficient molecules. The most important hurdle for the development of a STAT3 inhibitor as potential therapeutics will be the demonstration of their anti-tumor efficacy in in vivo systems and lack of toxicity in relevant animal models of human cancer.

\section{Conflict of interest statement}

None.

\section{Acknowledgements}

This research work was supported by grants from Singapore Ministry of Health's National Medical Research Council to GS under its Individual research grants funding scheme. APK was supported by grants from the National Medical Research Council of Singapore [Grant R713-000-124-213] and Cancer Science Institute of Singapore, Experimental Therapeutics I Program [Grant R-713-001-011-271].

\section{References}

[1] Q. Mo, S. Wang, V.E. Seshan, A.B. Olshen, N. Schultz, C. Sander, R.S. Powers, M. Ladanyi, R. Shen, Pattern discovery and cancer gene identification in integrated cancer genomic data, Proc. Natl. Acad. Sci. U. S. A. 110 (2013) 4245-4250.

[2] B.S. Taylor, N. Schultz, H. Hieronymus, A. Gopalan, Y. Xiao, B.S. Carver, V.K. Arora, P. Kaushik, E. Cerami, B. Reva, Integrative genomic profiling of human prostate cancer, Cancer Cell 18 (2010) 11-22.

[3] B.B. Aggarwal, R.V. Vijayalekshmi, B. Sung, Targeting inflammatory pathways for prevention and therapy of cancer: short-term friend, long-term foe, Clin. Cancer Res. 15 (2009) 425-430.

[4] P. Anand, A.B. Kunnumakkara, C. Sundaram, K.B. Harikumar, S.T. Tharakan, O.S. Lai, B. Sung, B.B. Aggarwal, Cancer is a preventable disease that requires major lifestyle changes, Pharm. Res. 25 (2008) 2097-2116

[5] D.M. Parkin, The global health burden of infection-associated cancers in the year 2002, Int. J. Cancer 118 (2006) 3030-3044.

[6] D. Belpomme, P. Irigaray, L. Hardell, R. Clapp, L. Montagnier, S. Epstein, A.J. Sasco, The multitude and diversity of environmental carcinogens, Environ. Res. 105 (2007) 414-429.

[7] W.W. Lin, M. Karin, A cytokine-mediated link between innate immunity, inflammation, and cancer, J. Clin. Invest. 117 (2007) 1175-1183.

[8] B.B. Aggarwal, G. Sethi, K.S. Ahn, S.K. Sandur, M.K. Pandey, A.B. Kunnumakkara, B Sung, H. Ichikawa, Targeting signal-transducer-and-activator-of-transcription-3 for prevention and therapy of cancer: modern target but ancient solution, Ann. N. Y. Acad. Sci. 1091 (2006) 151-169.

[9] J.E. Darnell Jr., I.M. Kerr, G.R. Stark, Jak-STAT pathways and transcriptional activation in response to IFNs and other extracellular signaling proteins, Science 264 (1994) 1415-1420.
[10] B.B. Aggarwal, A.B. Kunnumakkara, K.B. Harikumar, S.R. Gupta, S.T. Tharakan, C. Koca, S. Dey, B. Sung, Signal transducer and activator of transcription-3, inflammation, and cancer, Ann. N. Y. Acad. Sci. 1171 (2009) 59-76.

[11] B.B. Aggarwal, P. Gehlot, Inflammation and cancer: how friendly is the relationship for cancer patients? Curr. Opin. Pharmacol. 9 (2009) 351-369.

[12] S. Akira, Y. Nishio, M. Inoue, X.J. Wang, S. We, T. Matsusaka, K. Yoshida, T. Sudo, M. Naruto, T. Kishimoto, Molecular cloning of APRF, a novel IFN-stimulated gene factor 3 p91-related transcription factor involved in the gp130-mediated signaling pathway, Cell 77 (1994) 63-71.

[13] H. Yu, D. Pardoll, R. Jove, STATs in cancer inflammation and immunity: a leading role for STAT3, Nat. Rev. Cancer 9 (2009) 798-809.

[14] J. Turkson, R. Jove, STAT proteins: novel molecular targets for cancer drug discovery, Oncogene 19 (2000) 6613-6626.

[15] S. Haftchenary, M. Avadisian, P.T. Gunning, Inhibiting aberrant Stat3 function with molecular therapeutics: a progress report, Anticancer Drugs 22 (2011) 115-127.

[16] A. Yoshimura, T. Naka, M. Kubo, SOCS proteins, cytokine signalling and immune regulation, Nat. Rev. Immunol. 7 (2007) 454-465.

17] P. Sansone, G. Storci, S. Tavolari, T. Guarnieri, C. Giovannini, M. Taffurelli, C. Ceccarelli, D. Santini, P. Paterini, K.B. Marcu, P. Chieco, M. Bonafe, IL-6 triggers malignant features in mammospheres from human ductal breast carcinoma and normal mammary gland, J. Clin. Invest. 117 (2007) 3988-4002.

[18] W. Yin, S. Cheepala, J.N. Roberts, K. Syson-Chan, J. DiGiovanni, J.L. Clifford, Active Stat3 is required for survival of human squamous cell carcinoma cells in serum-free conditions, Mol. Cancer 5 (2006) 15.

[19] D.E. Levy, C.-k. Lee, What does Stat3 do? J. Clin. Invest. 109 (2002) 1143-1148.

[20] A. Subramaniam, M.K. Shanmugam, E. Perumal, F. Li, A. Nachiyappan, X. Dai, S.N. Swamy, K.S. Ahn, A.P. Kumar, B.K. Tan, K.M. Hui, G. Sethi, Potential role of signal transducer and activator of transcription (STAT)3 signaling pathway in inflammation, survival, proliferation and invasion of hepatocellular carcinoma, Biochim. Biophys. Acta, Rev. Cancer 1835 (2013) 46-60.

[21] N.G. Copeland, D.J. Gilbert, C. Schindler, Z. Zhong, Z. Wen, J.E. Darnell Jr., A.L. Mui, A. Miyajima, F.W. Quelle, J.N. Ihle, et al., Distribution of the mammalian Stat gene family in mouse chromosomes, Genomics 29 (1995) 225-228.

[22] D.R. Robinson, Y.-M. Wu, S. Kalyana-Sundaram, X. Cao, R.J. Lonigro, Y.-S. Sung, C.-L. Chen, L. Zhang, R. Wang, F. Su, Identification of recurrent NAB2-STAT6 gene fusions in solitary fibrous tumor by integrative sequencing, Nat. Genet. 45 (2013) 180-185.

[23] H.L. Koskela, S. Eldfors, P. Ellonen, A.J. van Adrichem, H. Kuusanmäki, E.I. Andersson, S. Lagström, M.J. Clemente, T. Olson, S.E. Jalkanen, Somatic STAT3 mutations in large granular lymphocytic leukemia, N. Engl. J. Med. 366 (2012) 1905-1913.

[24] H.L. Rajala, S. Eldfors, H. Kuusanmäki, A.J. van Adrichem, T. Olson, S. Lagström, E.I. Andersson, A. Jerez, M.J. Clemente, Y. Yan, Discovery of somatic STAT5b mutations in large granular lymphocytic leukemia, Blood 121 (2013) 4541-4550.

[25] D. Mangnall, N.C. Bird, A.W. Majeed, The molecular physiology of liver regeneration following partial hepatectomy, Liver Int. 23 (2003) 124-138.

[26] Y. Yamanaka, K. Nakajima, T. Fukada, M. Hibi, T. Hirano, Differentiation and growth arrest signals are generated through the cytoplasmic region of gp130 that is essential for Stat3 activation, EMBO J. 15 (1996) 1557-1565.

[27] O. Gires, F. Kohlhuber, E. Kilger, M. Baumann, A. Kieser, C. Kaiser, R. Zeidler, B. Scheffer, M. Ueffing, W. Hammerschmidt, Latent membrane protein 1 of Epstein-Barr virus interacts with JAK3 and activates STAT proteins, EMBO J. 18 (1999) 3064-3073.

[28] H. Wang, F. Lafdil, X. Kong, B. Gao, Signal transducer and activator of transcription 3 in liver diseases: a novel therapeutic target, Int. J. Biol. Sci. 7 (2011) 536-550.

[29] D.F. Calvisi, S. Ladu, A. Gorden, M. Farina, E.A. Conner, J.S. Lee, V.M. Factor, S.S. Thorgeirsson, Ubiquitous activation of Ras and Jak/Stat pathways in human HCC, Gastroenterology 130 (2006) 1117-1128.

[30] T. Hirano, K. Ishihara, M. Hibi, Roles of STAT3 in mediating the cell growth, differentiation and survival signals relayed through the IL-6 family of cytokine receptors, Oncogene 19 (2000) 2548-2556.

[31] P. Weerasinghe, Y. Li, Y. Guan, R. Zhang, D.J. Tweardy, N. Jing, T40214/PEI complex: a potent therapeutics for prostate cancer that targets STAT3 signaling, Prostate 68 (2008) 1430-1442.

[32] V.C. de Araújo, C. Furuse, P.R. Cury, A. Altemani, N.S. de Araújo, STAT3 expression in salivary gland tumours, Oral Oncol. 44 (2008) 439-445.

[33] S.H. Chen, D. Murphy, W. Lassoued, G. Thurston, M.D. Feldman, W.M. Lee, Activated STAT3 is a mediator and biomarker of VEGF endothelial activation, Cancer Biol. Ther. 7 (2008) 1994-2003.

[34] R.J. Chen, Y.S. Ho, H.R. Guo, Y.J. Wang, Rapid activation of Stat3 and ERK1/2 by nicotine modulates cell proliferation in human bladder cancer cells, Toxicol. Sci. 104 (2008) 283-293.

[35] J. Yang, X. Liao, M.K. Agarwal, L. Barnes, P.E. Auron, G.R. Stark, Unphosphorylated STAT3 accumulates in response to IL- 6 and activates transcription by binding to NFkappaB, Genes Dev. 21 (2007) 1396-1408.

[36] S.I. Grivennikov, M. Karin, Dangerous liaisons: STAT3 and NF-kappaB collaboration and crosstalk in cancer, Cytokine Growth Factor Rev. 21 (2010) 11-19.

[37] B.D. Page, D.P. Ball, P.T. Gunning, Signal transducer and activator of transcription 3 inhibitors: a patent review, Expert Opin. Ther. Pat. 21 (2011) 65-83.

[38] S. Fletcher, J.A. Drewry, V.M. Shahani, B.D. Page, P.T. Gunning, Molecular disruption of oncogenic signal transducer and activator of transcription 3 (STAT3) protein, Biochem. Cell Biol. 87 (2009) 825-833.

[39] N. Jing, D.J. Tweardy, Targeting Stat3 in cancer therapy, Anticancer Drugs 16 (2005) 601-607.

[40] X. Xu, M.M. Kasembeli, X. Jiang, B.J. Tweardy, D.J. Tweardy, Chemical probes that competitively and selectively inhibit Stat3 activation, PLoS One 4 (2009) e4783. 
[41] M. Totrov, R. Abagyan, Flexible protein-ligand docking by global energy optimization in internal coordinates, Proteins Suppl. 1 (1997) 215-220.

[42] A.K. Mankan, F.R. Greten, Inhibiting signal transducer and activator of transcription 3: rationality and rationale design of inhibitors, Expert Opin. Investig. Drugs 20 (2011) 1263-1275.

[43] J. Turkson, S. Zhang, J. Palmer, H. Kay, J. Stanko, L.B. Mora, S. Sebti, H. Yu, R. Jove, Inhibition of constitutive signal transducer and activator of transcription 3 activation by novel platinum complexes with potent antitumor activity, Mol. Cancer Ther. 3 (2004) 1533-1542.

[44] J. Turkson, S. Zhang, L.B. Mora, A. Burns, S. Sebti, R. Jove, A novel platinum compound inhibits constitutive Stat3 signaling and induces cell cycle arrest and apoptosis of malignant cells, J. Biol. Chem. 280 (2005) 32979-32988.

[45] N. Meydan, T. Grunberger, H. Dadi, M. Shahar, E. Arpaia, Z. Lapidot, J.S. Leeder, M. Freedman, A. Cohen, A. Gazit, A. Levitzki, C.M. Roifman, Inhibition of acute lymphoblastic leukaemia by a Jak-2 inhibitor, Nature 379 (1996) 645-648.

[46] K. Al Zaid Siddiquee, J. Turkson, STAT3 as a target for inducing apoptosis in solid and hematological tumors, Cell Res. 18 (2008) 254-267.

[47] R. Catlett-Falcone, T.H. Landowski, M.M. Oshiro, J. Turkson, A. Levitzki, R. Savino, G. Ciliberto, L. Moscinski, J.L. Fernandez-Luna, G. Nunez, W.S. Dalton, R. Jove, Constitutive activation of Stat3 signaling confers resistance to apoptosis in human U266 myeloma cells, Immunity 10 (1999) 105-115.

[48] P.C. Heinrich, I. Behrmann, G. Müller-Newen, F. Schaper, L. Graeve, Interleukin-6-type cytokine signalling through the gp130/Jak/STAT pathway, Biochem. J. 334 (1998) 297-314.

[49] A. Quaglino, C. Schere-Levy, L. Romorini, R.P. Meiss, E.C. Kordon, Mouse mammary tumors display Stat3 activation dependent on leukemia inhibitory factor signaling, Breast Cancer Res. 9 (2007) R69.

[50] J. Fukuzawa, G.W. Booz, R.A. Hunt, N. Shimizu, V. Karoor, K.M. Baker, D.E. Dostal, Cardiotrophin-1 increases angiotensinogen mRNA in rat cardiac myocytes through STAT3 an autocrine loop for hypertrophy, Hypertension 35 (2000) 1191-1196.

[51] W.M. Peterson, Q. Wang, R. Tzekova, S.J. Wiegand, Ciliary neurotrophic factor and stress stimuli activate the Jak-STAT pathway in retinal neurons and glia, J. Neurosci. 20 (2000) 4081-4090.

[52] B.A. Stout, M.E. Bates, L.Y. Liu, N.N. Farrington, P.J. Bertics, IL-5 and granulocyte-macrophage colony-stimulating factor activate STAT3 and STAT5 and promote Pim- 1 and cyclin D3 protein expression in human eosinophils, J. Immunol. 173 (2004) 6409-6417.

[53] A. Yamasaki, A. Saleh, L. Koussih, S. Muro, A.J. Halayko, A.S. Gounni, IL-9 induces CCL11 expression via STAT3 signalling in human airway smooth muscle cells, PLoS One 5 (2010) e9178.

[54] C. Niemand, A. Nimmesgern, S. Haan, P. Fischer, F. Schaper, R. Rossaint, P.C. Heinrich, G. Müller-Newen, Activation of STAT3 by IL-6 and IL-10 in primary human macrophages is differentially modulated by suppressor of cytokine signaling 3, J. Immunol. 170 (2003) 3263-3272.

[55] M. Ernst, M. Najdovska, D. Grail, T. Lundgren-May, M. Buchert, H. Tye, V.B. Matthews, J. Armes, P.S. Bhathal, N.R. Hughes, STAT3 and STAT1 mediate IL-11-dependent and inflammation-associated gastric tumorigenesis in gp130 receptor mutant mice, J. Clin. Invest. 118 (2008) 1727-1738.

[56] N.G. Jacobson, S.J. Szabo, R.M. Weber-Nordt, Z. Zhong, R.D. Schreiber, J. Darnell, K.M. Murphy, Interleukin 12 signaling in T helper type 1 (Th1) cells involves tyrosine phosphorylation of signal transducer and activator of transcription (Stat) 3 and Stat4, J. Exp. Med. 181 (1995) 1755-1762.

[57] J. Dien Bard, P. Gelebart, M. Anand, Z. Zak, S.A. Hegazy, H.M. Amin, R. Lai, IL-21 contributes to JAK3/STAT3 activation and promotes cell growth in ALK-positive anaplastic large cell lymphoma, Am. J. Pathol. 175 (2009) 825-834.

[58] R. Jiang, H. Wang, L. Deng, J. Hou, R. Shi, M. Yao, Y. Gao, A. Yao, X. Wang, L. Yu, IL-22 is related to development of human colon cancer by activation of STAT3, BMC Cancer 13 (2013) 59.

[59] J. Diegelmann, T. Olszak, B. Göke, R.S. Blumberg, S. Brand, A novel role for interleukin-27 (IL-27) as mediator of intestinal epithelial barrier protection mediated via differential signal transducer and activator of transcription (STAT) protein signaling and induction of antibacterial and anti-inflammatory proteins, J. Biol. Chem. 287 (2012) 286-298.

[60] T. Kordula, M. Bugno, J. Goldstein, J. Travis, Activation of signal transducer and activator of transcription-3 (Stat3) expression by interferon- $\gamma$ and interleukin- 6 in hepatoma cells, Biochem. Biophys. Res. Commun. 216 (1995) 999-1005.

[61] S. Miscia, M. Marchisio, A. Grilli, V. Di Valerio, L. Centurione, G. Sabatino, F. Garaci, G. Zauli, E. Bonvini, A. Di Baldassarre, Tumor necrosis factor alpha (TNF-alpha) activates Jak1/Stat3-Stat5B signaling through TNFR-1 in human B cells, Cell Growth Differ. 13 (2002) 13-18.

[62] N. Nadiminty, J.Y. Chun, Y. Hu, S. Dutt, X. Lin, A.C. Gao, LIGHT, a member of the TNF superfamily, activates Stat3 mediated by NIK pathway, Biochem. Biophys. Res. Commun. 359 (2007) 379-384.

[63] M. Mellado, J. Rodriguez-Frade, A. Aragay, G. Del Real, A. Martin, A. Vila-Coro, A. Serrano, F. Mayor, The chemokine monocyte chemotactic protein 1 triggers Janus kinase 2 activation and tyrosine phosphorylation of the CCR2B receptor, J. Immunol. 161 (1998) 805-813.

[64] M. Wong, E.N. Fish, RANTES and MIP-1 $\alpha$ activate Stats in T cells, J. Biol. Chem. 273 (1998) 309-314.

[65] A. Gotoh, H. Takahira, C. Mantel, S. Litz-Jackson, H.S. Boswell, H.E. Broxmeyer, Steel factor induces serine phosphorylation of Stat3 in human growth factor-dependent myeloid cell lines, Blood 88 (1996) 138-145.

[66] S. Fossey, M. Bear, W. Kisseberth, M. Pennell, C. London, Oncostatin M promotes STAT3 activation, VEGF production, and invasion in osteosarcoma cell lines, BMC Cancer 11 (2011) 125.

[67] O.K. Park, T.S. Schaefer, D. Nathans, In vitro activation of Stat3 by epidermal growth factor receptor kinase, Proc. Natl. Acad. Sci. U. S. A. 93 (1996) 13704-13708.
[68] M.L. Vignais, H.B. Sadowski, D. Watling, N.C. Rogers, M. Gilman, Platelet-derived growth factor induces phosphorylation of multiple JAK family kinases and STAT proteins, Mol. Cell. Biol. 16 (1996) 1759-1769.

[69] T. Takahashi, K. Fukuda, J. Pan, H. Kodama, M. Sano, S. Makino, T. Kato, T. Manabe, S. Ogawa, Characterization of insulin-like growth factor-1-induced activation of the JAK/STAT pathway in rat cardiomyocytes, Circ. Res. 85 (1999) 884-891.

[70] S.S. Tian, P. Lamb, H. Seidel, R. Stein, J. Rosen, Rapid activation of the STAT3 transcription factor by granulocyte colony-stimulating factor, Blood 84 (1994) 1760-1764.

[71] U. Novak, A. Harpur, L. Paradiso, V. Kanagasundaram, A. Jaworowski, A. Wilks, J Hamilton, Colony-stimulating factor 1-induced STAT1 and STAT3 activation is accompanied by phosphorylation of Tyk2 in macrophages and Tyk2 and JAK1 in fibroblasts, Blood 86 (1995) 2948-2956.

[72] D. Cao, T.L. Tal, L.M. Graves, I. Gilmour, W. Linak, W. Reed, P.A. Bromberg, J.M Samet, Diesel exhaust particulate-induced activation of Stat3 requires activities of EGFR and Src in airway epithelial cells, Am. J. Physiol. Lung Cell. Mol. Physiol. 292 (2007) L422-L429.

[73] R.S. Tacke, A. Tosello-Trampont, V. Nguyen, D.W. Mullins, Y.S. Hahn, Extracellular hepatitis C virus core protein activates STAT3 in human monocytes/macrophages/ dendritic cells via an IL-6 autocrine pathway, J. Biol. Chem. 286 (2011) 10847-10855.

[74] V.S. Carl, J.K. Gautam, L.D. Comeau, M.F. Smith, Role of endogenous IL-10 in LPS-induced STAT3 activation and IL-1 receptor antagonist gene expression, J. Leukoc. Biol. 76 (2004) 735-742.

[75] T. Bito, N. Sumita, T. Masaki, T. Shirakawa, M. Ueda, R. Yoshiki, Y. Tokura, C. Nishigori, Ultraviolet light induces Stat3 activation in human keratinocytes and fibroblasts through reactive oxygen species and DNA damage, Exp. Dermatol. 19 (2010) 654-660.

[76] P. Gatsios, L. Terstegen, F. Schliess, D. Häussinger, I.M. Kerr, P.C. Heinrich, L. Graeve Activation of the Janus kinase/signal transducer and activator of transcription pathway by osmotic shock, J. Biol. Chem. 273 (1998) 22962-22968.

[77] L. Tacchini, D. Fusar-Poli, M. Sironi, A. Mantovani, A. Bernelli-Zazzera, Activation of signal transducer and activator of transcription 3 in rat liver after heat shock and reperfusion stress, Int. J. Biochem. Cell Biol. 35 (2003) 316-323.

[78] E. Burova, I. Gonchar, N. Nikol'skil̆, STAT1 and STAT3 activation by oxidative stress in A431 cells involves Src-dependent EGF receptor transactivation, Tsitologiia 45 (2003) 466-467.

[79] C.P. Kung, D.G. Meckes, N. Raab-Traub, Epstein-Barr virus LMP1 activates EGFR, STAT3, and ERK through effects on PKC $\delta$, J. Virol. 85 (2011) 4399-4408.

[80] Z. Percario, E. Olivetta, G. Fiorucci, G. Mangino, S. Peretti, G. Romeo, E. Affabris, M. Federico, Human immunodeficiency virus type 1 (HIV-1) Nef activates STAT3 in primary human monocyte/macrophages through the release of soluble factors: involvement of Nef domains interacting with the cell endocytotic machinery, J. Leukoc. Biol. 74 (2003) 821-832.

[81] Y. Liu, L. Lv, W. Xiao, C. Gong, J. Yin, D. Wang, H. Sheng, Leptin activates STAT3 and ERK1/2 pathways and induces endometrial cancer cell proliferation, J. Huazhong Univ. Sci. Technolog. Med. Sci. 31 (2011) 365-370.

[82] J. Si, S.J. Collins, Activated Ca2 +/Calmodulin-dependent protein kinase II $\gamma$ is a critical regulator of myeloid leukemia cell proliferation, Cancer Res. 68 (2008) 3733-3742.

[83] K. Dvorak, M. Chavarria, C.M. Payne, L. Ramsey, C. Crowley-Weber, B. Dvorakova, B. Dvorak, H. Bernstein, H. Holubec, R.E. Sampliner, Activation of the interleukin-6/STAT3 antiapoptotic pathway in esophageal cells by bile acids and low pH: relevance to barrett's esophagus, Clin. Cancer Res. 13 (2007) 5305-5313.

[84] E. Jang, J. Moon, J. Ko, C. Ahn, H. Lee, J. Shin, C. Park, J. Kang, Novel black soy peptides with antiobesity effects: activation of leptin-like signaling and AMP-activated protein kinase, Int. J. Obes. 32 (2008) 1161-1170.

[85] Y.J. Hsieh, H. Wakiyama, S. Levitsky, J.D. McCully, Cardioplegia and diazoxide modulate STAT3 activation and DNA binding, Ann. Thorac. Surg. 84 (2007) 1272-1278.

[86] W. An, J. Yang, Y. Ao, Metallothionein mediates cardioprotection of isoliquiritigenin against ischemia-reperfusion through JAK2/STAT3 activation, Acta Pharmacol. Sin. 27 (2006) 1431-1437.

[87] N. Muma, R. Singh, M. Vercillo, D. D'Souza, B. Zemaitaitis, F. Garcia, K. Damjanoska, Y. Zhang, G. Battaglia, L. Van de Kar, Chronic olanzapine activates the Stat3 signal transduction pathway and alters expression of components of the $5-\mathrm{HT}_{2 \mathrm{~A}}$ receptor signaling system in rat frontal cortex, Neuropharmacology 53 (2007) 552-562.

[88] B. Debnath, S. Xu, N. Neamati, Small molecule inhibitors of signal transducer and activator of transcription 3 (Stat3) protein, J. Med. Chem. 55 (2012) 6645-6668.

[89] P.A. Johnston, J.R. Grandis, STAT3 signaling: anticancer strategies and challenges, Mol. Interv. 11 (2011) 18-26.

[90] C.M. Silva, Role of STATs as downstream signal transducers in Src family kinase-mediated tumorigenesis, Oncogene 23 (2004) 8017-8023.

[91] P.T. Ram, R. lyengar, G protein coupled receptor signaling through the Src and Stat3 pathway: role in proliferation and transformation, Oncogene 20 (2001) 1601-1606.

[92] H. Yu, M. Kortylewski, D. Pardoll, Crosstalk between cancer and immune cells: role of STAT3 in the tumour microenvironment, Nat. Rev. Immunol. 7 (2007) 41-51.

[93] G.M. Delgoffe, D.A. Vignali, STAT heterodimers in immunity: a mixed message or a unique signal? JAK-STAT 2 (2013) e23060.

[94] U. Novak, A. Mui, A. Miyajima, L. Paradiso, Formation of STAT5-containing DNA binding complexes in response to colony-stimulating factor-1 and plateletderived growth factor, J. Biol. Chem. 271 (1996) 18350-18354.

[95] S. Haan, J.F. Keller, I. Behrmann, P.C. Heinrich, C. Haan, Multiple reasons for an inefficient STAT1 response upon IL-6-type cytokine stimulation, Cell. Signal. 17 (2005) 1542-1550.

[96] C. Guzzo, N.F.C. Mat, K. Gee, Interleukin-27 induces a STAT1/3-and NF-кBdependent proinflammatory cytokine profile in human monocytes, J. Biol. Chem. 285 (2010) 24404-24411. 
[97] J. Ma, X. Cao, Regulation of Stat3 nuclear import by importin $\alpha 5$ and importin $\alpha 7$ via two different functional sequence elements, Cell. Signal. 18 (2006) 1117-1126.

[98] K. Yokogami, S. Wakisaka, J. Avruch, S.A. Reeves, Serine phosphorylation and maximal activation of STAT3 during CNTF signaling is mediated by the rapamycin target mTOR, Curr. Biol. 10 (2000) 47-50.

[99] N. Jain, T. Zhang, W.H. Kee, W. Li, X. Cao, Protein kinase C $\delta$ associates with and phosphorylates Stat3 in an interleukin-6-dependent manner, J. Biol. Chem. 274 (1999) 24392-24400.

[100] A.K. Fu, W.Y. Fu, A.K. Ng, W.W. Chien, Y.P. Ng, J.H. Wang, N.Y. Ip, Cyclin-dependent kinase 5 phosphorylates signal transducer and activator of transcription 3 and regulates its transcriptional activity, Proc. Natl. Acad. Sci. U. S. A. 101 (2004) 6728-6733.

[101] M.H. Aziz, H.T. Manoharan, J.M. Sand, A.K. Verma, Protein kinase C $\varepsilon$ interacts with Stat 3 and regulates its activation that is essential for the development of skin cancer, Mol. Carcinog. 46 (2007) 646-653.

[102] D.A. Frank, STAT3 as a central mediator of neoplastic cellular transformation, Cancer Lett. 251 (2007) 199-210.

[103] M.J. Gray, J. Zhang, L.M. Ellis, G.L. Semenza, D.B. Evans, S.S. Watowich, G.E. Gallick, HIF-1 $\alpha$, STAT3, CBP/p300 and Ref-1/APE are components of a transcriptional complex that regulates Src-dependent hypoxia-induced expression of VEGF in pancreatic and prostate carcinomas, Oncogene 24 (2005) 3110-3120.

[104] S. Giraud, F. Bienvenu, S. Avril, H. Gascan, D.M. Heery, O. Coqueret, Functional interaction of STAT3 transcription factor with the coactivator NcOA/SRC1a, J. Biol. Chem. 277 (2002) 8004-8011.

[105] Z.L. Yuan, Y.J. Guan, D. Chatterjee, Y.E. Chin, Stat3 dimerization regulated by reversible acetylation of a single lysine residue, Sci. Signal. 307 (2005) 269-273.

[106] X. Chen, U. Vinkemeier, Y. Zhao, D. Jeruzalmi, J.E. Darnell Jr., J. Kuriyan, Crystal structure of a tyrosine phosphorylated STAT-1 dimer bound to DNA, Cell 93 (1998) 827-839.

[107] J. Yang, G.R. Stark, Roles of unphosphorylated STATs in signaling, Cell Res. 18 (2008) 443-451.

[108] D. Masciocchi, A. Gelain, S. Villa, F. Meneghetti, D. Barlocco, Signal transducer and activator of transcription 3 (STAT3): a promising target for anticancer therapy, Future Med. Chem. 3 (2011) 567-597.

[109] V.N. Ivanov, M. Krasilnikov, Z.e. Ronai, Regulation of Fas expression by STAT3 and c-Jun is mediated by phosphatidylinositol 3-kinase-AKT signaling, J. Biol. Chem. 277 (2002) 4932-4944.

[110] J.F. Bromberg, M.H. Wrzeszczynska, G. Devgan, Y. Zhao, R.G. Pestell, C. Albanese, J.E. Darnell Jr., Stat3 as an Oncogene, Cell 98 (1999) 295-303.

[111] H. Yu, R. Jove, The STATs of cancer-new molecular targets come of age, Nat. Rev Cancer 4 (2004) 97-105.

[112] J.R. Grandis, S.D. Drenning, A. Chakraborty, M.Y. Zhou, Q. Zeng, A.S. Pitt, D.J. Tweardy, Requirement of Stat3 but not Stat1 activation for epidermal growth factor receptor-mediated cell growth In vitro, J. Clin. Invest. 102 (1998) 1385-1392.

[113] S.K. Chai, G.L. Nichols, P. Rothman, Constitutive activation of JAKs and STATs in BCR-Abl-expressing cell lines and peripheral blood cells derived from leukemic patients, J. Immunol. 159 (1997) 4720-4728.

[114] C.L. Yu, R. Jove, S. Burakoff, Constitutive activation of the Janus kinase-STAT pathway in T lymphoma overexpressing the Lck protein tyrosine kinase, J. Immunol. 159 (1997) 5206-5210.

[115] A.C. Bharti, S. Shishodia, J.M. Reuben, D. Weber, R. Alexanian, S. Raj-Vadhan, Z Estrov, M. Talpaz, B.B. Aggarwal, Nuclear factor-кB and STAT3 are constitutively active in CD138 + cells derived from multiple myeloma patients, and suppression of these transcription factors leads to apoptosis, Blood 103 (2004) 3175-3184.

[116] S.O. Rahaman, P.C. Harbor, O. Chernova, G.H. Barnett, M.A. Vogelbaum, S.J. Haque, Inhibition of constitutively active Stat3 suppresses proliferation and induces apoptosis in glioblastoma multiforme cells, Oncogene 21 (2002) 8404-8413.

[117] G. Niu, T. Bowman, M. Huang, S. Shivers, D. Reintgen, A. Daud, A. Chang, A. Kraker, R. Jove, H. Yu, Roles of activated Src and Stat3 signaling in melanoma tumor cell growth, Oncogene 21 (2002) 7001-7010.

[118] C.I. Sartor, M.L. Dziubinski, C.L. Yu, R. Jove, S.P. Ethier, Role of epidermal growth factor receptor and STAT-3 activation in autonomous proliferation of SUM-102PT human breast cancer cells, Cancer Res. 57 (1997) 978-987.

[119] L. Cai, G. Zhang, X. Tong, Q. You, Y. An, Y. Wang, L. Guo, T. Wang, D. Zhu, J. Zheng, Growth inhibition of human ovarian cancer cells by blocking STAT3 activation with small interfering RNA, Eur. J. Obstet. Gynecol. Reprod. Biol. 148 (2010) 73-80.

[120] C. Chen, F. Hsieh, J. Lieblein, J. Brown, C. Chan, J. Wallace, G. Cheng, B. Hall, J. Lin, Stat3 activation in human endometrial and cervical cancers, Br. J. Cancer 96 (2007) 591-599.

121] F.M. Corvinus, C. Orth, R. Moriggl, S.A. Tsareva, S. Wagner, E.B. Pfitzner, D. Baus, R Kaufmann, L.A. Huberb, K. Zatloukal, Persistent STAT3 activation in colon cancer is associated with enhanced cell proliferation and tumor growth, Neoplasia 7 (2005) 545-555.

[122] D. Wei, X. Le, L. Zheng, L. Wang, J.A. Frey, A.C. Gao, Z. Peng, S. Huang, H.Q Xiong J.L Abbruzzese, Stat3 activation regulates the expression of vascular endothelial growth factor and human pancreatic cancer angiogenesis and metastasis, Oncogene 22 (2003) 319-329.

[123] M.G. Alexandrow, L.J. Song, S. Altiok, J. Gray, E.B. Haura, N.B. Kumar, Curcumin: a novel Stat3 pathway inhibitor for chemoprevention of lung cancer, Eur. J. Cancer Prev. 21 (2012) 407-412.

[124] L.K. Schaefer, Z. Ren, G.N. Fuller, T.S. Schaefer, Constitutive activation of Stat3alpha in brain tumors: localization to tumor endothelial cells and activation by the endothelial tyrosine kinase receptor VEGFR-2, Oncogene 21 (2002) 2058-2065.

[125] C. Guo, G. Yang, K. Khun, X. Kong, D. Levy, P. Lee, J. Melamed, Activation of Stat3 in renal tumors, Am. J. Transl. Res. 1 (2009) 283-290.

[126] J. Abdulghani, L. Gu, A. Dagvadorj, J. Lutz, B. Leiby, G. Bonuccelli, M.P. Lisanti, T. Zellweger, K. Alanen, T. Mirtti, Stat3 promotes metastatic progression of prostate cancer, Am. J. Pathol. 172 (2008) 1717-1728.

[127] A. Jarnicki, T. Putoczki, M. Ernst, Stat3: linking inflammation to epithelial cancer-more than a "gut" feeling? Cell Div. 5 (2010) 1-15.

[128] C.J. Greenhalgh, D.J. Hilton, Negative regulation of cytokine signaling, J. Leukoc. Biol. 70 (2001) 348-356.

[129] B. He, L. You, K. Uematsu, K. Zang, Z. Xu, A.Y. Lee, J.F. Costello, F. McCormick, D.M. Jablons, SOCS-3 is frequently silenced by hypermethylation and suppresses cell growth in human lung cancer, Proc. Natl. Acad. Sci. U. S. A. 100 (2003) 14133-14138.

[130] S. Veeriah, C. Brennan, S. Meng, B. Singh, J.A. Fagin, D.B. Solit, P.B. Paty, D. Rohle, I. Vivanco, J. Chmielecki, The tyrosine phosphatase PTPRD is a tumor suppressor that is frequently inactivated and mutated in glioblastoma and other human cancers, Proc. Natl. Acad. Sci. U. S. A. 106 (2009) 9435-9440

[131] K. Chan, S. Sano, K. Kataoka, E. Abel, S. Carbajal, L. Beltran, J. Clifford, M. Peavey, J. Shen, J. Digiovanni, Forced expression of a constitutively active form of Stat3 in mouse epidermis enhances malignant progression of skin tumors induced by two-stage carcinogenesis, Oncogene 27 (2007) 1087-1094.

[132] G. Niu, K.H. Shain, M. Huang, R. Ravi, A. Bedi, W.S. Dalton, R. Jove, H. Yu, Overexpression of a dominant-negative signal transducer and activator of transcription 3 variant in tumor cells leads to production of solublefactors that induce apoptosis and cell cycle arrest, Cancer Res. 61 (2001) 3276-3280.

[133] R. Chiarle, W.J. Simmons, H. Cai, G. Dhall, A. Zamo, R. Raz, J.G. Karras, D.E. Levy, G. Inghirami, Stat3 is required for ALK-mediated lymphomagenesis and provides a possible therapeutic target, Nat. Med. 11 (2005) 623-629.

[134] G. Niu, R. Heller, R. Catlett-Falcone, D. Coppola, M. Jaroszeski, W. Dalton, R. Jove, H. $\mathrm{Yu}, \mathrm{Gene}$ therapy with dominant-negative Stat3 suppresses growth of the murine melanoma B16 tumor in vivo, Cancer Res. 59 (1999) 5059-5063.

[135] T. Fukada, M. Hibi, Y. Yamanaka, M. Takahashi-Tezuka, Y. Fujitani, T. Yamaguchi, K. Nakajima, T. Hirano, Two signals are necessary for cell proliferation induced by a cytokine receptor gp130: involvement of STAT3 in anti-apoptosis, Immunity 5 (1996) 449-460.

[136] L. Li, P.E. Shaw, Autocrine-mediated activation of STAT3 correlates with cell proliferation in breast carcinoma lines, J. Biol. Chem. 277 (2002) 17397-17405.

[137] N. Kanda, H. Seno, Y. Konda, H. Marusawa, M. Kanai, T. Nakajima, T. Kawashima, A. Nanakin, T. Sawabu, Y. Uenoyama, STAT3 is constitutively activated and supports cell survival in association with survivin expression in gastric cancer cells, Oncogene 23 (2004) 4921-4929.

[138] J. Bollrath, T.J. Phesse, V.A. von Burstin, T. Putoczki, M. Bennecke, T. Bateman, T. Nebelsiek, T. Lundgren-May, Ö. Canli, S. Schwitalla, gp130-mediated Stat3 activation in enterocytes regulates cell survival and cell-cycle progression during colitis-associated tumorigenesis, Cancer Cell 15 (2009) 91-102.

[139] C.L. Chen, L. Cen, J. Kohout, B. Hutzen, C. Chan, F.C. Hsieh, A. Loy, V. Huang, G. Cheng, J. Lin, Signal transducer and activator of transcription 3 activation is associated with bladder cancer cell growth and survival, Mol. Cancer 7 (2008) 78.

[140] M. Masuda, M. Suzui, R. Yasumatu, T. Nakashima, Y. Kuratomi, K. Azuma, K. Tomita, S. Komiyama, I.B. Weinstein, Constitutive activation of signal transducers and activators of transcription 3 correlates with cyclin D1 overexpression and may provide a novel prognostic marker in head and neck squamous cell carcinoma, Cancer Res. 62 (2002) 3351-3355.

[141] J. Yang, M. Chatterjee-Kishore, S.M. Staugaitis, H. Nguyen, K. Schlessinger, D.E. Levy, G.R. Stark, Novel roles of unphosphorylated STAT3 in oncogenesis and transcriptional regulation, Cancer Res. 65 (2005) 939-947.

[142] T. Fukada, T. Ohtani, Y. Yoshida, T. Shirogane, K. Nishida, K. Nakajima, M. Hibi, T. Hirano, STAT3 orchestrates contradictory signals in cytokine-induced G1 to S cell-cycle transition, EMBO J. 17 (1998) 6670-6677.

[143] G.C. Prendergast, Mechanisms of apoptosis by c-Myc, Oncogene 18 (1999) 2967-2987.

[144] T. Shirogane, T. Fukada, J.M. Muller, D.T. Shima, M. Hibi, T. Hirano, Synergistic roles for Pim-1 and c-Myc in STAT3-mediated cell cycle progression and antiapoptosis, Immunity 11 (1999) 709-719.

[145] S.H. Zhao, F. Zhao, J.Y. Zheng, L.F. Gao, X.J. Zhao, M.H. Cui, Knockdown of stat3 expression by RNAi inhibits in vitro growth of human ovarian cancer, Radiol. Oncol. 45 (2011) 196-203.

[146] S. Pensa, G. Regis, D. Boselli, F. Novelli, V. Poli, STAT1 and STAT3 in Tumorigenesis: Two Sides of the Same Coin? Landes Bioscience, 2009.

[147] H. Xiong, Z.G. Zhang, X.Q. Tian, D.F. Sun, Q.C. Liang, Y.J. Zhang, R. Lu, Y.X. Chen, J.Y. Fang, Inhibition of JAK1, 2/STAT3 signaling induces apoptosis, cell cycle arrest, and reduces tumor cell invasion in colorectal cancer cells, Neoplasia 10 (2008) 287-297.

[148] K. Takeda, T. Kaisho, N. Yoshida, J. Takeda, T. Kishimoto, S. Akira, Stat3 activation is responsible for IL-6-dependent $\mathrm{T}$ cell proliferation through preventing apoptosis: generation and characterization of T cell-specific Stat3-deficient mice, J. Immunol. 161 (1998) 4652-4660.

[149] V.N. Ivanov, A. Bhoumik, M. Krasilnikov, R. Raz, L.B. Owen-Schaub, D. Levy, C.M. Horvath, Z.e. Ronai, Cooperation between STAT3 and c-Jun suppresses Fas transcription, Mol. Cell 7 (2001) 517-528.

[150] D. Feng, H. Zheng, Y. Tan, R. Cheng, Effect of phosphorylation of MAPK and Stat3 and expression of c-fos and c-jun proteins on hepatocarcinogenesis and their clinical significance, World J. Gastroenterol. 7 (2001) 33-36. 
[151] H. Nakagami, R. Morishita, K. Yamamoto, Y. Taniyama, M. Aoki, K. Matsumoto, T. Nakamura, Y. Kaneda, M. Horiuchi, T. Ogihara, Mitogenic and antiapoptotic actions of hepatocyte growth factor through ERK, STAT3, and Akt in endothelial cells, Hypertension 37 (2001) 581-586.

[152] Z. Wei, X. Jiang, H. Qiao, B. Zhai, L. Zhang, Q. Zhang, Y. Wu, H. Jiang, X. Sun, STAT3 interacts with Skp2/p27/p21 pathway to regulate the motility and invasion of gastric cancer cells, Cell. Signal. 25 (2013) 931-938.

[153] E. Zorzi, P. Bonvini, Inducible Hsp70 in the regulation of cancer cell survival: analysis of chaperone induction, expression and activity, Cancers 3 (2011) 3921-3956.

[154] H. Lee, J. Deng, M. Kujawski, C. Yang, Y. Liu, A. Herrmann, M. Kortylewski, D. Horne G. Somlo, S. Forman, STAT3-induced S1PR1 expression is crucial for persistent STAT3 activation in tumors, Nat. Med. 16 (2010) 1421-1428.

[155] H. Dalwadi, K. Krysan, N. Heuze-Vourc'h, M. Dohadwala, D. Elashoff, S. Sharma, N. Cacalano, A. Lichtenstein, S. Dubinett, Cyclooxygenase-2-dependent activation of signal transducer and activator of transcription 3 by interleukin- 6 in non-small cell lung cancer, Clin. Cancer Res. 11 (2005) 7674-7682.

[156] H. Lee, A. Herrmann, J.H. Deng, M. Kujawski, G. Niu, Z. Li, S. Forman, R. Jove, D.M. Pardoll, H. Yu, Persistently activated Stat 3 maintains constitutive NF-kB activity in tumors, Cancer Cell 15 (2009) 283-293.

[157] L. Samavati, R. Rastogi, W. Du, M. Hüttemann, A. Fite, L. Franchi, STAT3 tyrosine phosphorylation is critical for interleukin 1 beta and interleukin-6 production in response to lipopolysaccharide and live bacteria, Mol. Immunol. 46 (2009) 1867-1877.

[158] Y. Li, H. Du, Y. Qin, J. Roberts, O.W. Cummings, C. Yan, Activation of the signal transducers and activators of the transcription 3 pathway in alveolar epithelial cells induces inflammation and adenocarcinomas in mouse lung, Cancer Res. 67 (2007) 8494-8503.

[159] S. Sano, S. Itami, K. Takeda, M. Tarutani, Y. Yamaguchi, H. Miura, K. Yoshikawa, S. Akira, J. Takeda, Keratinocyte-specific ablation of Stat3 exhibits impaired skin remodeling, but does not affect skin morphogenesis, EMBO J. 18 (1999) 4657-4668.

[160] R.A. Steinman, A. Wentzel, Y. Lu, C. Stehle, J.R. Grandis, Activation of Stat3 by cell confluence reveals negative regulation of Stat3 by cdk2, Oncogene 22 (2003) 3608-3615.

[161] A. Vultur, J. Cao, R. Arulanandam, J. Turkson, R. Jove, P. Greer, A. Craig, B. Elliott, L. Raptis, Cell-to-cell adhesion modulates Stat 3 activity in normal and breast carcinoma cells, Oncogene 23 (2004) 2600-2616.

[162] D.J. Dauer, B. Ferraro, L. Song, B. Yu, L. Mora, R. Buettner, S. Enkemann, R. Jove, E.B. Haura, Stat3 regulates genes common to both wound healing and cancer, Oncogene 24 (2005) 3397-3408.

[163] C. Suiqing, Z. Min, C. Lirong, Overexpression of phosphorylated-STAT3 correlated with the invasion and metastasis of cutaneous squamous cell carcinoma, J. Dermatol. 32 (2005) 354-360.

[164] I.C. Gaemers, H.L. Vos, H.H. Volders, S.W. van der Valk, J. Hilkens, A stat-responsive element in the promoter of the episialin/MUC1 gene is involved in its overexpression in carcinoma cells, J. Biol. Chem. 276 (2001) 6191-6199.

[165] W. Guo, Y. Pylayeva, A. Pepe, T. Yoshioka, W.J. Muller, G. Inghirami, F.G. Giancotti, B4 integrin amplifies ErbB2 signaling to promote mammary tumorigenesis, Cell 126 (2006) 489-502.

[166] J. Azare, K. Leslie, H. Al-Ahmadie, W. Gerald, P.H. Weinreb, S.M. Violette, J. Bromberg, Constitutively activated Stat3 induces tumorigenesis and enhances cell motility of prostate epithelial cells through integrin $\beta 6$, Mol. Cell. Biol. 27 (2007) 4444-4453.

[167] D.L. Silver, H. Naora, J. Liu, W. Cheng, D.J. Montell, Activated Signal Transducer and Activator of Transcription (STAT) 3: Localization in focal adhesions and function in ovarian cancer cell motility, Cancer Res. 64 (2004) 3550-3558.

[168] D.C.H. Ng, B.H. Lin, C.P. Lim, G. Huang, T. Zhang, V. Poli, X. Cao, Stat3 regulates microtubules by antagonizing the depolymerization activity of stathmin, Sci. Signal. 172 (2006) 245-257.

[169] D. Kesanakurti, C. Chetty, D.R. Maddirela, M. Gujrati, J. Rao, Essential role of cooperative NF- $\kappa$ B and Stat3 recruitment to ICAM-1 intronic consensus elements in the regulation of radiation-induced invasion and migration in glioma, Oncogene 32 (2012) 5144-5155.

[170] T.N. Dechow, L. Pedranzini, A. Leitch, K. Leslie, W.L. Gerald, I. Linkov, J.F. Bromberg, Requirement of matrix metalloproteinase- 9 for the transformation of human mammary epithelial cells by Stat3-C, Proc. Natl. Acad. Sci. U. S. A. 101 (2004) 10602-10607.

[171] Y. Song, L. Qian, S. Song, L. Chen, Y. Zhang, G. Yuan, H. Zhang, Q. Xia, M. Hu, M. Yu, Fra-1 and Stat3 synergistically regulate activation of human MMP-9 gene, Mol. Immunol. 45 (2008) 137-143.

[172] T.X. Xie, D. Wei, M. Liu, A.C. Gao, F. Ali-Osman, R. Sawaya, S. Huang, Stat3 activation regulates the expression of matrix metalloproteinase- 2 and tumor invasion and metastasis, Oncogene 23 (2004) 3550-3560.

[173] M. Itoh, T. Murata, T. Suzuki, M. Shindoh, K. Nakajima, K. Imai, K. Yoshida, Requirement of STAT3 activation for maximal collagenase-1 (MMP-1) induction by epidermal growth factor and malignant characteristics in T24 bladder cancer cells, Oncogene 25 (2005) 1195-1204.

[174] S.A. Tsareva, R. Moriggl, F.M. Corvinus, B. Wiederanders, A. Schütz, B. Kovacic, K. Friedrich, Signal transducer and activator of transcription 3 activation promotes invasive growth of colon carcinomas through matrix metalloproteinase induction, Neoplasia 9 (2007) 279-291.

[175] W.C. Li, S.L. Ye, R.X. Sun, Y.K. Liu, Z.Y. Tang, Y. Kim, J.G. Karras, H. Zhang, Inhibition of growth and metastasis of human hepatocellular carcinoma by antisense oligonucleotide targeting signal transducer and activator of transcription 3, Clin. Cancer Res. 12 (2006) 7140-7148.
[176] T.X. Xie, F.J. Huang, K.D. Aldape, S.-H. Kang, M. Liu, J.E. Gershenwald, K. Xie, R. Sawaya, S. Huang, Activation of Stat3 in human melanoma promotes brain metastasis, Cancer Res. 66 (2006) 3188-3196.

[177] G.Z. Cheng, W. Zhang, M. Sun, Q. Wang, D. Coppola, M. Mansour, L. Xu, C. Costanzo J.Q. Cheng, L.H. Wang, Twist is transcriptionally induced by activation of STAT3 and mediates STAT3 oncogenic function, J. Biol. Chem. 283 (2008) 14665-14673.

[178] X.l. Zhao, T. Sun, N. Che, D. Sun, N. Zhao, X.y. Dong, Q. Gu, Z. Yao, B.c. Sun, Promotion of hepatocellular carcinoma metastasis through matrix metalloproteinase activation by epithelial-mesenchymal transition regulator Twist1, J. Cell. Mol. Med. 15 (2011) 691-700.

[179] H. Okamura, K. Yoshida, T. Haneji, Negative regulation of TIMP1 is mediated by transcription factor TWIST1, Int. J. Oncol. 35 (2009) 181-186.

[180] M. Kira, S. Sano, S. Takagi, K. Yoshikawa, J. Takeda, S. Itami, STAT3 deficiency in keratinocytes leads to compromised cell migration through hyperphosphorylation of p130 cas, J. Biol. Chem. 277 (2002) 12931-12936.

[181] D. Valdembri, G. Serini, A. Vacca, D. Ribatti, F. Bussolino, In vivo activation of JAK2/STAT-3 pathway during angiogenesis induced by GM-CSF, FASEB J. 16 (2002) 225-227.

[182] G. Niu, K.L. Wright, M. Huang, L. Song, E. Haura, J. Turkson, S. Zhang, T. Wang, D. Sinibaldi, D. Coppola, R. Heller, L.M. Ellis, J. Karras, J. Bromberg, D. Pardoll, R. Jove $\mathrm{H}$. Yu, Constitutive Stat3 activity up-regulates VEGF expression and tumor angiogenesis, Oncogene 21 (2002) 2000-2008.

[183] L.H. Wei, M.L. Kuo, C.A. Chen, C.H. Chou, K.B. Lai, C.N. Lee, C.Y. Hsieh, Interleukin-6 promotes cervical tumor growth by VEGF-dependent angiogenesis via a STAT3 pathway, Oncogene 22 (2003) 1517-1527.

[184] A.D. Laird, G. Li, K.G. Moss, R.A. Blake, M.A. Broome, J.M. Cherrington, D.B. Mendel, Src family kinase activity is required for signal tranducer and activator of transcription 3 and focal adhesion kinase phosphorylation and vascular endothelial growth factor signaling in vivo and for anchorage-dependent and -independent growth of human tumor cells, Mol. Cancer Ther. 2 (2003) 461-469.

[185] M. Kujawski, M. Kortylewski, H. Lee, A. Herrmann, H. Kay, H. Yu, Stat3 mediates myeloid cell-dependent tumor angiogenesis in mice, J. Clin. Invest. 118 (2008) 3367-3377.

[186] J.H. Chio, M.J. Ahn, C.K. Park, H.X. Han, S.J. Kwon, Y.Y. Lee, I.S. Kim, Phospho-Stat3 expression and correlation with VEGF, p53, and Bcl-2 in gastric carcinoma using tissue microarray, APMIS 114 (2006) 619-625.

[187] M. Zhao, F.H. Gao, J.Y. Wang, F. Liu, H.H. Yuan, W.Y. Zhang, B. Jiang, JAK2/STAT3 signaling pathway activation mediates tumor angiogenesis by upregulation of VEGF and bFGF in non-small-cell lung cancer, Lung Cancer 73 (2011) 366-374.

[188] G.L. Semenza, Involvement of hypoxia-inducible factor 1 in human cancer, Intern. Med. 41 (2002) 79-83

[189] Q. Xu, J. Briggs, S. Park, G. Niu, M. Kortylewski, S. Zhang, T. Gritsko, J. Turkson, H. Kay, G.L. Semenza, Targeting Stat3 blocks both HIF-1 and VEGF expression induced by multiple oncogenic growth signaling pathways, Oncogene 24 (2005) $5552-5560$

[190] J.E. Jung, H.G. Lee, I.H. Cho, D.H. Chung, S.H. Yoon, Y.M. Yang, J.W. Lee, S. Choi, J.W. Park, S.K. Ye, M.H. Chung, STAT3 is a potential modulator of HIF-1-mediated VEGF expression in human renal carcinoma cells, FASEB J. 19 (2005) 1296-1298.

[191] G. Niu, K.L. Wright, Y. Ma, G.M. Wright, M. Huang, R. Irby, J. Briggs, J. Karras, W.D. Cress, D. Pardoll, R. Jove, J. Chen, H. Yu, Role of Stat3 in regulating p53 expression and function, Mol. Cell. Biol. 25 (2005) 7432-7440.

[192] B.B. Aggarwal, G. Sethi, V. Baladandayuthapani, S. Krishnan, S. Shishodia, Targeting cell signaling pathways for drug discovery: an old lock needs a new key, J. Cell. Biochem. 102 (2007) 580-592.

[193] D.J. Hanahan, D. Papahadjopoulos, Interactions of phospholipids with coagulation factors, Thromb. Diath. Haemorrh. Suppl. 17 (1965) 71-84.

[194] M.J. Renan, How many mutations are required for tumorigenesis? Implications from human cancer data, Mol. Carcinog. 7 (1993) 139-146.

[195] M.K. Pandey, B. Sung, B.B. Aggarwal, Betulinic acid suppresses STAT3 activation pathway through induction of protein tyrosine phosphatase SHP-1 in human multiple myeloma cells, Int. J. Cancer 127 (2010) 282-292.

[196] B.B. Aggarwal, S. Shishodia, Molecular targets of dietary agents for prevention and therapy of cancer, Biochem. Pharmacol. 71 (2006) 1397-1421.

[197] S.H. Lee, G.S. Seo, H.S. Kim, S.W. Woo, G. Ko, D.H. Sohn, 2',4',6'Tris(methoxymethoxy) chalcone attenuates hepatic stellate cell proliferation by a heme oxygenase-dependent pathway, Biochem. Pharmacol. 72 (2006) 1322-1333.

[198] Y. Wang, F.L. Chan, S. Chen, L.K. Leung, The plant polyphenol butein inhibits testosterone-induced proliferation in breast cancer cells expressing aromatase, Life Sci. 77 (2005) 39-51.

199] H.S. Jang, S.H. Kook, Y.O. Son, J.G. Kim, Y.M. Jeon, Y.S. Jang K.C. Choi, J. Kim, S.K. Han, K.Y. Lee, B.K. Park, N.P. Cho, J.C. Lee, Flavonoids purified from Rhus verniciflua Stokes actively inhibit cell growth and induce apoptosis in human osteosarcoma cells, Biochim. Biophys. Acta 1726 (2005) 309-316.

[200] H.M. Kang, J.H. Kim, M.Y. Lee, K.H. Son, D.C. Yang N.I. Baek, B.M. Kwon, Relationship between flavonoid structure and inhibition of farnesyl protein transferase, Nat. Prod. Res. 18 (2004) 349-356.

[201] E. Aizu, T. Nakadate, S. Yamamoto, R. Kato, Inhibition of 12-O-tetradecanoylphorbol13-acetate-mediated epidermal ornithine decarboxylase induction and skin tumor promotion by new lipoxygenase inhibitors lacking protein kinase $C$ inhibitory effects, Carcinogenesis 7 (1986) 1809-1812.

[202] C. Selvam, S.M. Jachak, K.K. Bhutani, Cyclooxygenase inhibitory flavonoids from the stem bark of Semecarpus anacardium Linn, Phytother. Res. 18 (2004) 582-584.

[203] K. Hayashi, T. Nagamatsu, S. Honda, Y. Suzuki, Butein (3,4,2',4'-tetrahydroxychalcone) ameliorates experimental anti-glomerular basement membrane antibody-associated glomerulonephritis (3), Eur. J. Pharmacol. 316 (1996) 297-306. 
[204] S.H. Lee, J.X. Nan, Y.Z. Zhao, S.W. Woo, E.J. Park, T.H. Kang, G.S. Seo, Y.C. Kim, D.H. Sohn, The chalcone butein from Rhus verniciflua shows antifibrogenic activity, Planta Med. 69 (2003) 990-994.

[205] D.O. Moon, M.O. Kim, Y.H. Choi, J.W. Hyun, W.Y. Chang, G.Y. Kim, Butein induces $\mathrm{G}(2) / \mathrm{M}$ phase arrest and apoptosis in human hepatoma cancer cells through ROS generation, Cancer Lett. 288 (2010) 204-213.

[206] P. Rajendran, T.H. Ong, L. Chen, F. Li, M.K. Shanmugam, S. Vali, T. Abbasi, S. Kapoor, A. Sharma, A.P. Kumar, K.M. Hui, G. Sethi, Suppression of signal transducer and activator of transcription 3 activation by butein inhibits growth of human hepatocellular carcinoma in vivo, Clin. Cancer Res. 17 (2011) 1425-1439.

[207] M. Kurdi, G.W. Booz, Evidence that IL-6-type cytokine signaling in cardiomyocytes is inhibited by oxidative stress: parthenolide targets JAK1 activation by generating ROS, J. Cell. Physiol. 212 (2007) 424-431.

[208] M. Nardini, P. Pisu, V. Gentili, F. Natella, M. Di Felice, E. Piccolella, C. Scaccini, Effect of caffeic acid on tert-butyl hydroperoxide-induced oxidative stress in U937, Free Radic. Biol. Med. 25 (1998) 1098-1105.

[209] H. Tapiero, K.D. Tew, G.N. Ba, G. Mathe, Polyphenols: do they play a role in the prevention of human pathologies? Biomed. Pharmacother. 56 (2002) 200-207.

[210] M. Nardini, F. Leonardi, C. Scaccini, F. Virgili, Modulation of ceramide-induced NF-kappaB binding activity and apoptotic response by caffeic acid in U937 cells: comparison with other antioxidants, Free Radic. Biol. Med. 30 (2001) $722-733$.

[211] M. Nardini, C. Scaccini, L. Packer, F. Virgili, In vitro inhibition of the activity of phosphorylase kinase, protein kinase $\mathrm{C}$ and protein kinase $\mathrm{A}$ by caffeic acid and a procyanidin-rich pine bark (Pinus marittima) extract, Biochim. Biophys. Acta 1474 (2000) 219-225.

[212] A. Russo, R. Longo, A. Vanella, Antioxidant activity of propolis: role of caffeic acid phenethyl ester and galangin, Fitoterapia 73 (2002) S21-S29.

[213] K. Natarajan, S. Singh, T.R. Burke Jr., D. Grunberger, B.B. Aggarwal, Caffeic acid phenethyl ester is a potent and specific inhibitor of activation of nuclear transcription factor NF-kappa B, Proc. Natl. Acad. Sci. U. S. A. 93 (1996) 9090-9095.

[214] T.W. Chung, S.K. Moon, Y.C. Chang, J.H. Ko, Y.C. Lee, G. Cho, S.H. Kim, J.G. Kim, C.H. Kim, Novel and therapeutic effect of caffeic acid and caffeic acid phenyl ester on hepatocarcinoma cells: complete regression of hepatoma growth and metastasis by dual mechanism, FASEB J. 18 (2004) 1670-1681.

[215] J.E. Jung, H.S. Kim, C.S. Lee, D.H. Park, Y.N. Kim, M.J. Lee, J.W. Lee, J.W. Park, M.S Kim, S.K. Ye, M.H. Chung, Caffeic acid and its synthetic derivative CADPE suppress tumor angiogenesis by blocking STAT3-mediated VEGF expression in human renal carcinoma cells, Carcinogenesis 28 (2007) 1780-1787.

[216] N. Ferrara, VEGF as a therapeutic target in cancer, Oncology 69 (2005) 11-16.

[217] M. Hockel, P. Vaupel, Tumor hypoxia: definitions and current clinical, biologic, and molecular aspects, J. Natl. Cancer Inst. 93 (2001) 266-276.

[218] G. Pagès, J. Pouysségur, Transcriptional regulation of the Vascular Endothelial Growth Factor gene-a concert of activating factors, Cardiovasc. Res. 65 (2005) 564-573.

[219] T. Nagaoka, A.H. Banskota, Y. Tezuka, I. Saiki, S. Kadota, Selective antiproliferative activity of caffeic acid phenethyl ester analogues on highly liver-metastatic murine colon 26-L5 carcinoma cell line, Bioorg. Med. Chem. 10 (2002) 3351-3359.

[220] P. Michaluart, J.L. Masferrer, A.M. Carothers, K. Subbaramaiah, B.S. Zweifel, C. Koboldt, J.R. Mestre, D. Grunberger, P.G. Sacks, T. Tanabe, A.J. Dannenberg, Inhibitory effects of caffeic acid phenethyl ester on the activity and expression of cyclooxygenase- 2 in human oral epithelial cells and in a rat model of inflammation, Cancer Res. 59 (1999) 2347-2352.

[221] C.S. Kim, W.H. Park, J.Y. Park, J.H. Kang, M.O. Kim, T. Kawada, H. Yoo, I.S. Han, R. Yu, Capsaicin, a spicy component of hot pepper, induces apoptosis by activation of the peroxisome proliferator-activated receptor gamma in HT-29 human colon cancer cells, J. Med. Food 7 (2004) 267-273.

[222] M. Bhutani, A.K. Pathak, A.S. Nair, A.B. Kunnumakkara, S. Guha, G. Sethi, B.B Aggarwal, Capsaicin is a novel blocker of constitutive and interleukin-6-inducible STAT3 activation, Clin. Cancer Res. 13 (2007) 3024-3032.

[223] P. Rajendran, F. Li, M.K. Shanmugam, R. Kannaiyan, J.N. Goh, K.F. Wong, W. Wang, E. Khin, V. Tergaonkar, A.P. Kumar, J.M. Luk, G. Sethi, Celastrol suppresses growth and induces apoptosis of human hepatocellular carcinoma through the modulation of STAT3/JAK2 signaling cascade in vitro and in vivo, Cancer Prev. Res. 5 (2012) 631-643.

[224] R. Kannaiyan, H.S. Hay, P. Rajendran, F. Li, M.K. Shanmugam, S. Vali, T. Abbasi, S. Kapoor, A. Sharma, A.P. Kumar, W.J. Chng, G. Sethi, Celastrol inhibits proliferation and induces chemosensitization through down-regulation of NF-kappaB and STAT3 regulated gene products in multiple myeloma cells, Br. J. Pharmacol. 164 (2011) 1506-1521.

[225] X. Pang, Z. Yi, J. Zhang, B. Lu, B. Sung, W. Qu, B.B. Aggarwal, M. Liu, Celastrol suppresses angiogenesis-mediated tumor growth through inhibition of AKT/mammalian target of rapamycin pathway, Cancer Res. 70 (2010) 1951-1959.

[226] Z. Lu, Y. Jin, L. Qiu, Y. Lai, J. Pan, Celastrol, a novel HSP90 inhibitor, depletes Bcr-Abl and induces apoptosis in imatinib-resistant chronic myelogenous leukemia cells harboring T315I mutation, Cancer Lett. 290 (2010) 182-191.

[227] C.L. Yu, D.J. Meyer, G.S. Campbell, A.C. Larner, C. Carter-Su, J. Schwartz, R. Jove, Enhanced DNA-binding activity of a Stat3-related protein in cells transformed by the Src oncoprotein, Science 269 (1995) 81-83.

[228] M.M. Brierley, E.N. Fish, Stats: multifaceted regulators of transcription, J. Interferon Cytokine Res. 25 (2005) 733-744.

[229] D.M. Moran, M.A. Mattocks, P.A. Cahill, L.G. Koniaris, I.H. McKillop, Interleukin-6 mediates $\mathrm{G}(0) / \mathrm{G}(1)$ growth arrest in hepatocellular carcinoma through a STAT 3-dependent pathway, J. Surg. Res. 147 (2008) 23-33.
[230] B.B. Aggarwal, A.B. Kunnumakkara, K.B. Harikumar, S.R. Gupta, S.T. Tharakan, C. Koca, S. Dey, B. Sung, Signal transducer and activator of transcription-3, inflammation, and cancer: how intimate is the relationship? Ann. N. Y. Acad. Sci. 1171 (2009) 59-76.

[231] D. Paris, N.J. Ganey, V. Laporte, N.S. Patel, D. Beaulieu-Abdelahad, C. Bachmeier, A. March, G. Ait-Ghezala, M.J. Mullan, Reduction of beta-amyloid pathology by celastrol in a transgenic mouse model of Alzheimer's disease, J. Neuroinflammation 7 (2010) 17.

[232] Y. Dai, J.T. DeSano, Y. Meng, O. Ji, M. Ljungman, T.S. Lawrence, L. Xu, Celastrol potentiates radiotherapy by impairment of DNA damage processing in human prostate cancer, Int. J. Radiat. Oncol. Biol. Phys. 74 (2009) 1217-1225.

[233] R. Kannaiyan, M.K. Shanmugam, G. Sethi, Molecular targets of celastrol derived from Thunder of God Vine: potential role in the treatment of inflammatory disorders and cancer, Cancer Lett. 303 (2011) 9-20.

[234] G. Sethi, K.S. Ahn, M.K. Pandey, B.B. Aggarwal, Celastrol, a novel triterpene, potentiates TNF-induced apoptosis and suppresses invasion of tumor cells by inhibiting NF-kappaB-regulated gene products and TAK1-mediated NF-kappaB activation, Blood 109 (2007) 2727-2735.

[235] K.T. Chan, K. Li, S.L. Liu, K.H. Chu, M. Toh, W.D. Xie, Cucurbitacin B inhibits STAT3 and the Raf/MEK/ERK pathway in leukemia cell line K562, Cancer Lett. 289 (2010) 46-52.

[236] J.C. Chen, M.H. Chiu, R.L. Nie, G.A. Cordell, S.X. Qiu, Cucurbitacins and cucurbitane glycosides: structures and biological activities, Nat. Prod. Rep. 22 (2005) 386-399.

[237] B. Jayaprakasam, N.P. Seeram, M.G. Nair, Anticancer and antiinflammatory activities of cucurbitacins from Cucurbita andreana, Cancer Lett. 189 (2003) 11-16.

[238] D. Meng, S. Qiang, L. Lou, W. Zhao, Cytotoxic cucurbitane-type triterpenoids from Elaeocarpus hainanensis, Planta Med. 74 (2008) 1741-1744.

[239] M.R. Farias, E.P. Schenkel, R. Mayer, G. Rucker, Cucurbitacins as constituents of Wilbrandia ebracteata, Planta Med. 59 (1993) 272-275.

[240] E. Yesilada, S. Tanaka, E. Sezik, M. Tabata, Isolation of an anti-inflammatory principle from the fruit juice of Ecballium elaterium, J. Nat. Prod. 51 (1988) 504-508.

[241] M. Zhang, H. Zhang, C. Sun, X. Shan, X. Yang, J. Li-Ling, Y. Deng, Targeted constitutive activation of signal transducer and activator of transcription 3 in human hepatocellular carcinoma cells by cucurbitacin B, Cancer Chemother. Pharmacol. 63 (2009) 635-642.

[242] D. Yin, N. Wakimoto, H. Xing, D. Lu, T. Huynh, X. Wang, K.L. Black, H.P. Koeffler, Cucurbitacin B markedly inhibits growth and rapidly affects the cytoskeleton in glioblastoma multiforme, Int. J. Cancer 123 (2008) 1364-1375.

[243] L. Costantino, D. Barlocco, STAT 3 as a target for cancer drug discovery, Curr. Med. Chem. 15 (2008) 834-843.

[244] T. Liu, M. Zhang, H. Zhang, C. Sun, Y. Deng, Inhibitory effects of cucurbitacin B on laryngeal squamous cell carcinoma, Eur. Arch. Otorhinolaryngol. 265 (2008) 1225-1232.

[245] C. Zhang, B. Li, X. Zhang, P. Hazarika, B.B. Aggarwal, M. Duvic, Curcumin selectively induces apoptosis in cutaneous T-cell lymphoma cell lines and patients' PBMCs: potential role for STAT-3 and NF-kappaB signaling, J. Invest. Dermatol. 130 (2010) 2110-2119.

[246] S. Uddin, A.R. Hussain, P.S. Manogaran, K. Al-Hussein, L.C. Platanias, M.I. Gutierrez, K.G. Bhatia, Curcumin suppresses growth and induces apoptosis in primary effusion lymphoma, Oncogene 24 (2005) 7022-7030.

[247] S. Pal, T. Choudhuri, S. Chattopadhyay, A. Bhattacharya, G.K. Datta, T. Das, G. Sa, Mechanisms of curcumin-induced apoptosis of Ehrlich's ascites carcinoma cells, Biochem. Biophys. Res. Commun. 288 (2001) 658-665.

[248] R.A. Sharma, S.A. Euden, S.L. Platton, D.N. Cooke, A. Shafayat, H.R. Hewitt, T.H. Marczylo, B. Morgan, D. Hemingway, S.M. Plummer, M. Pirmohamed, A.J. Gescher, W.P. Steward, Phase I clinical trial of oral curcumin: biomarkers of systemic activity and compliance, Clin. Cancer Res. 10 (2004) 6847-6854.

[249] N. Dhillon, B.B. Aggarwal, R.A. Newman, R.A. Wolff, A.B. Kunnumakkara, J.L. Abbruzzese, C.S. Ng, V. Badmaev, R. Kurzrock, Phase II trial of curcumin in patients with advanced pancreatic cancer, Clin. Cancer Res. 14 (2008) 4491-4499.

[250] P. Anand, A.B. Kunnumakkara, R.A. Newman, B.B. Aggarwal, Bioavailability of curcumin: problems and promises, Mol. Pharm. 4 (2007) 807-818.

[251] J. Weissenberger, M. Priester, C. Bernreuther, S. Rakel, M. Glatzel, V. Seifert, D. Kogel, Dietary curcumin attenuates glioma growth in a syngeneic mouse model by inhibition of the JAK1,2/STAT3 signaling pathway, Clin. Cancer Res. 16 (2010) 5781-5795.

[252] A.C. Bharti, N. Donato, B.B. Aggarwal, Curcumin (diferuloylmethane) inhibits constitutive and IL-6-inducible STAT3 phosphorylation in human multiple myeloma cells, J. Immunol. 171 (2003) 3863-3871.

[253] B. Sung, S. Prasad, V.R. Yadav, B.B. Aggarwal, Cancer cell signaling pathways targeted by spice-derived nutraceuticals, Nutr. Cancer 64 (2012) 173-197.

[254] F. Li, P.P. Fernandez, P. Rajendran, K.M. Hui, G. Sethi, Diosgenin, a steroidal saponin, inhibits STAT3 signaling pathway leading to suppression of proliferation and chemosensitization of human hepatocellular carcinoma cells, Cancer Lett. 292 (2010) 197-207.

[255] K.S. Ahn, G. Sethi, B. Sung, A. Goel, R. Ralhan, B.B. Aggarwal, Guggulsterone, a farnesoid X receptor antagonist, inhibits constitutive and inducible STAT3 activation through induction of a protein tyrosine phosphatase SHP-1, Cancer Res. 68 (2008) 4406-4415.

[256] N.L. Urizar, A.B. Liverman, D.T. Dodds, F.V. Silva, P. Ordentlich, Y. Yan, F.J. Gonzalez, R.A. Heyman, D.J. Mangelsdorf, D.D. Moore, A natural product that lowers cholesterol as an antagonist ligand for FXR, Science 296 (2002) 1703-1706.

[257] S.V. Singh, S. Choi, Y. Zeng, E.R. Hahm, D. Xiao, Guggulsterone-induced apoptosis in human prostate cancer cells is caused by reactive oxygen intermediate dependent activation of c-Jun NH2-terminal kinase, Cancer Res. 67 (2007) 7439-7449.

[258] S. Shishodia, G. Sethi, K.S. Ahn, B.B. Aggarwal, Guggulsterone inhibits tumor cell proliferation, induces S-phase arrest, and promotes apoptosis through activation 
of c-Jun N-terminal kinase, suppression of Akt pathway, and downregulation of antiapoptotic gene products, Biochem. Pharmacol. 74 (2007) 118-130.

[259] N. Chakravarti, J.N. Myers, B.B. Aggarwal, Targeting constitutive and interleukin6-inducible signal transducers and activators of transcription 3 pathway in head and neck squamous cell carcinoma cells by curcumin (diferuloylmethane), Int. J. Cancer 119 (2006) 1268-1275.

[260] M. Kawano, T. Hirano, T. Matsuda, T. Taga, Y. Horii, K. Iwato, H. Asaoku, B. Tang, O. Tanabe, H. Tanaka, et al., Autocrine generation and requirement of BSF-2/IL-6 for human multiple myelomas, Nature 332 (1988) 83-85.

[261] Y. Han, H.M. Amin, B. Franko, C. Frantz, X. Shi, R. Lai, Loss of SHP1 enhances JAK3/STAT3 signaling and decreases proteosome degradation of JAK3 and NPM-ALK in ALK + anaplastic large-cell lymphoma, Blood 108 (2006) 2796-2803.

[262] K. Leslie, C. Lang, G. Devgan, J. Azare, M. Berishaj, W. Gerald, Y.B. Kim, K. Paz, J.E. Darnell, C. Albanese, T. Sakamaki, R. Pestell, J. Bromberg, Cyclin D1 is transcriptionally regulated by and required for transformation by activated signal transducer and activator of transcription 3, Cancer Res. 66 (2006) 2544-2552.

[263] R.J. Leeman-Neill, S.E. Wheeler, S.V. Singh, S.M. Thomas, R.R. Seethala, D.B. Neill, M.C. Panahandeh, E.R. Hahm, S.C. Joyce, M. Sen, Q. Cai, M.L. Freilino, C. Li, D.E. Johnson, J.R. Grandis, Guggulsterone enhances head and neck cancer therapies via inhibition of signal transducer and activator of transcription-3, Carcinogenesis 30 (2009) $1848-1856$

[264] M.A. Macha, A. Matta, S.S. Chauhan, K.W. Siu, R. Ralhan, Guggulsterone (GS) inhibits smokeless tobacco and nicotine-induced NF-KB and STAT3 pathways in head and neck cancer cells, Carcinogenesis 32 (2011) 368-380.

[265] T. Kijima, H. Niwa, R.A. Steinman, S.D. Drenning, W.E. Gooding, A.L. Wentzel, S. Xi, J.R. Grandis, STAT3 activation abrogates growth factor dependence and contributes to head and neck squamous cell carcinoma tumor growth in vivo, Cell Growth Differ. 13 (2002) 355-362.

[266] N.L. Urizar, D.D. Moore, GUGULIPID: a natural cholesterol-lowering agent, Annu. Rev. Nutr. 23 (2003) 303-313.

[267] S. Arora, S. Singh, G.A. Piazza, C.M. Contreras, J. Panyam, A.P. Singh, Honokiol: a novel natural agent for cancer prevention and therapy, Curr. Mol. Med. 12 (2012) 1244-1252.

[268] P. Rajendran, F. Li, M.K. Shanmugam, S. Vali, T. Abbasi, S. Kapoor, K.S. Ahn, A.P. Kumar, G. Sethi, Honokiol inhibits signal transducer and activator of transcription-3 signaling, proliferation, and survival of hepatocellular carcinoma cells via the protein tyrosine phosphatase SHP-1, J. Cell. Physiol. 227 (2012) 2184-2195.

[269] C. Jin, H. Li, Y. He, M. He, L. Bai, Y. Cao, W. Song, K. Dou, Combination chemotherapy of doxorubicin and paclitaxel for hepatocellular carcinoma in vitro and in vivo, J. Cancer Res. Clin. Oncol. 136 (2010) 267-274.

[270] K. Swiatek-Machado, J. Mieczkowski, A. Ellert-Miklaszewska, P. Swierk, I. Fokt, S. Szymanski, S. Skora, W. Szeja, G. Grynkiewicz, B. Lesyng, W. Priebe, B. Kaminska, Novel small molecular inhibitors disrupt the JAK/STAT3 and FAK signaling pathways and exhibit a potent antitumor activity in glioma cells, Cancer Biol. Ther. 13 (2012) 657-670.

[271] J. Deng, F. Grande, N. Neamati, Small molecule inhibitors of Stat3 signaling pathway, Curr. Cancer Drug Targets 7 (2007) 91-107.

[272] A. Iwamaru, S. Szymanski, E. Iwado, H. Aoki, T. Yokoyama, I. Fokt, K. Hess, C. Conrad, T. Madden, R. Sawaya, S. Kondo, W. Priebe, Y. Kondo, A novel inhibitor of the STAT3 pathway induces apoptosis in malignant glioma cells both in vitro and in vivo, Oncogene 26 (2007) 2435-2444.

[273] K. Siddiquee, S. Zhang, W.C. Guida, M.A. Blaskovich, B. Greedy, H.R. Lawrence, M.L. Yip, R. Jove, M.M. McLaughlin, N.J. Lawrence, S.M. Sebti, J. Turkson, Selective chemical probe inhibitor of Stat3, identified through structure-based virtual screening, induces antitumor activity, Proc. Natl. Acad. Sci. U. S. A. 104 (2007) 7391-7396.

[274] X. Zhang, J.E. Darnell Jr., Functional importance of Stat3 tetramerization in activation of the alpha 2-macroglobulin gene, J. Biol. Chem. 276 (2001) 33576-33581.

[275] Y. Zhang, S. Sif, J. DeWille, The mouse C/EBPdelta gene promoter is regulated by STAT3 and Sp1 transcriptional activators, chromatin remodeling and c-Myc repression, J. Cell. Biochem. 102 (2007) 1256-1270.
[276] D.R. Tyler, M.E. Persky, L.A. Matthews, S. Chan, J.D. Farrar, Pre-assembly of STAT4 with the human IFN-alpha/beta receptor-2 subunit is mediated by the STAT4 N-domain, Mol. Immunol. 44 (2007) 1864-1872.

[277] O.A. Timofeeva, V. Gaponenko, S.J. Lockett, S.G. Tarasov, S. Jiang, C.J. Michejda, A.O Perantoni, N.I. Tarasova, Rationally designed inhibitors identify STAT3 N-domain as a promising anticancer drug target, ACS Chem. Biol. 2 (2007) 799-809.

[278] K.M. Quesnelle, A.L. Boehm, J.R. Grandis, STAT-mediated EGFR signaling in cancer, J. Cell. Biochem. 102 (2007) 311-319.

[279] A.M. Egloff, J.R. Grandis, Improving response rates to EGFR-targeted therapies for head and neck squamous cell carcinoma: candidate predictive biomarkers and combination treatment with Src inhibitors, J. Oncol. 2009 (2009) 896407.

[280] F.P. Santos, H.M. Kantarjian, N. Jain, T. Manshouri, D.A. Thomas, G. Garcia-Manero, D. Kennedy, Z. Estrov, J. Cortes, S. Verstovsek, Phase 2 study of CEP-701, an orally available JAK2 inhibitor, in patients with primary or post-polycythemia vera/essential thrombocythemia myelofibrosis, Blood 115 (2010) 1131-1136

[281] A.F. Wilks, The JAK kinases: not just another kinase drug discovery target, Semin Cell Dev. Biol. 19 (2008) 319-328.

[282] A. Quintas-Cardama, K. Vaddi, P. Liu, T. Manshouri, J. Li, P.A. Scherle, E. Caulder X. Wen, Y. Li, P. Waeltz, M. Rupar, T. Burn, Y. Lo, J. Kelley, M. Covington, S. Shepard, J.D. Rodgers, P. Haley, H. Kantarjian, J.S. Fridman, S. Verstovsek, Preclinical characterization of the selective JAK1/2 inhibitor INCB018424: therapeutic implications for the treatment of myeloproliferative neoplasms, Blood 115 (2010) 3109-3117.

[283] R. Burger, S. Le Gouill, Y.T. Tai, R. Shringarpure, P. Tassone, P. Neri, K. Podar, L. Catley, T. Hideshima, D. Chauhan, E. Caulder, C.L. Neilan, K. Vaddi, J. Li, M. Gramatzki, J.S. Fridman, K.C. Anderson, Janus kinase inhibitor INCB20 has antiproliferative and apoptotic effects on human myeloma cells in vitro and in vivo, Mol. Cancer Ther. 8 (2009) 26-35.

[284] R.R. Nair, J.H. Tolentino, L.A. Hazlehurst, Role of STAT3 in Transformation and drug resistance in CML, Front Oncol. 2 (2012) 30.

[285] P. Coppo, I. Dusanter-Fourt, G. Millot, M.M. Nogueira, A. Dugray, M.L. Bonnet, M.T. Mitjavila-Garcia, D. Le Pesteur, F. Guilhot, W. Vainchenker, Constitutive and specific activation of STAT3 by BCR-ABL in embryonic stem cells, Oncogene 22 (2003) $4102-4110$

[286] P. Coppo, S. Flamant, V.D. Mas, P. Jarrier, M. Guillier, M.L. Bonnet C. Lacout, F. Guilhot, W. Vainchenker, A.G. Turhan, BCR-ABL activates STAT3 via JAK and MEK pathways in human cells, Br. J. Haematol. 134 (2006) 171-179.

[287] R.J. Leeman, V.W. Lui, J.R. Grandis, STAT3 as a therapeutic target in head and neck cancer, Expert. Opin. Biol. Ther. 6 (2006) 231-241.

[288] J. Schust, B. Sperl, A. Hollis, T.U. Mayer, T. Berg, Stattic: a small-molecule inhibitor of STAT3 activation and dimerization, Chem. Biol. 13 (2006) 1235-1242.

[289] A.L. Boehm, M. Sen, R. Seethala, W.E. Gooding, M. Freilino, S.M. Wong, S. Wang, D.E. Johnson, J.R. Grandis, Combined targeting of epidermal growth factor receptor, signal transducer and activator of transcription- 3 , and $\mathrm{Bcl}-\mathrm{X}(\mathrm{L})$ enhances antitumor effects in squamous cell carcinoma of the head and neck, Mol. Pharmacol. 73 (2008) 1632-1642.

[290] M. Sen, P.J. Tosca, C. Zwayer, M.J. Ryan, J.D. Johnson, K.A. Knostman, P.C. Giclas, J.O Peggins, J.E. Tomaszewski, T.P. McMurray, C. Li, M.S. Leibowitz, R.L. Ferris, W.E. Gooding, S.M. Thomas, D.E. Johnson, J.R. Grandis, Lack of toxicity of a STAT3 decoy oligonucleotide, Cancer Chemother. Pharmacol. 63 (2009) 983-995.

[291] S.K. Klosek, K. Nakashiro, S. Hara, H. Goda, H. Hamakawa, Stat3 as a molecular target in RNA interference-based treatment of oral squamous cell carcinoma, Oncol. Rep. 20 (2008) 873-878.

[292] M. Zhao, B. Jiang, F.H. Gao, Small molecule inhibitors of STAT3 for cancer therapy, Curr. Med. Chem. 18 (2011) 4012-4018.

[293] K. Liby, N. Voong, C.R. Williams, R. Risingsong D.B. Royce, T. Honda, G.W. Gribble, M.B. Sporn, J.J. Letterio, The synthetic triterpenoid CDDO-Imidazolide suppresses STAT phosphorylation and induces apoptosis in myeloma and lung cancer cells, Clin. Cancer Res. 12 (2006) 4288-4293.

[294] Z. Duan, R.Y. Ames, M. Ryan, F.J. Hornicek, H. Mankin, M.V. Seiden, CDDO-Me, a synthetic triterpenoid, inhibits expression of IL-6 and Stat3 phosphorylation in multi-drug resistant ovarian cancer cells, Cancer Chemother. Pharmacol. 63 (2009) $681-689$. 